\title{
Synthesis of Anatase TiO2 Microspheres and Their Efficient Performance in Dye-sensitized Solar Cell
}

\section{Gowthambabu V}

Sri Sivasubramaniya Nadar College of Engineering, Kalavakkam-603110

\section{Murnal Deshpande}

Sri Sivasubramaniya Nadar College of Engineering, Kalavakkam-603110

\section{Govindaraj R ( $\nabla$ isrogovindaraj@gmail.com )}

Sri Sivasubramaniya Nadar College of Engineering, Kalavakkam-603110 https://orcid.org/0000-0002-

6770-7495

\section{Nithesh Krishna V. K}

Sri Sivasubramaniya Nadar College of Engineering, Kalavakkam-603110

\section{Leela Charumathi M}

Sri Sivasubramaniya Nadar College of Engineering, Kalavakkam-603110

\section{Manish Kumar J}

Sri Sivasubramaniya Nadar College of Engineering, Kalavakkam-603110

Dhilip Vignesh M. S

Sri Sivasubramaniya Nadar College of Engineering, Kalavakkam-603110

Isaac Daniel R

Sri Sivasubramaniya Nadar College of Engineering, Kalavakkam-603110

Ramasamy $\mathbf{P}$

Sri Sivasubramaniya Nadar College of Engineering, Kalavakkam-603110

\section{Research Article}

Keywords: Titanium dioxide, Microsphere, Dye-sensitized solar cell, Photoanode

Posted Date: March 15th, 2021

DOl: https://doi.org/10.21203/rs.3.rs-282653/v1

License: (c) (i) This work is licensed under a Creative Commons Attribution 4.0 International License. Read Full License 


\title{
Synthesis of anatase $\mathrm{TiO}_{2}$ microspheres and their efficient performance in dye-sensitized solar cell
}

\author{
V. Gowthambabu ${ }^{\mathrm{a}}$, Murnal Deshpande ${ }^{\mathrm{b}}$, R. Govindaraj ${ }^{\mathrm{a}^{*}}$, V. K. Nithesh Krishna ${ }^{\mathrm{b}}$, M. Leela \\ Charumathi $^{\text {b }}$ J. Manish Kumar ${ }^{\mathrm{b}}$, M. S. Dhilip Vignesh ${ }^{\mathrm{b}}$, R. Isacc Daniel ${ }^{\mathrm{a}}$, P. Ramasamy ${ }^{\mathrm{a}}$ \\ ${ }^{a}$ Department of Physics, SSN Research Centre, Sri Sivasubramaniya Nadar College of \\ Engineering, Kalavakkam, Chennai, Tamilnadu 603 110, India \\ ${ }^{\mathrm{b}}$ Department of Electrical and Electronics Engineering, Sri Sivasubramaniya Nadar College \\ of Engineering, Kalavakkam, Chennai, Tamilnadu 603 110, India \\ Corresponding author: isrogovindaraj@gmail.com
}

\begin{abstract}
Nanomaterials play important role in performance of dye sensitized solar cells. In this paper, highly phase pure anatase $\mathrm{TiO}_{2}$ microspheres were synthesized using a low-cost hydrothermal route. Initially, X-ray diffraction studies and Raman spectroscopic analysis were carried out and the formation of tetragonal structure of $\mathrm{TiO}_{2}$ with the anatase phase was confirmed. The UV-Vis DRS studies showed the excellent reflectance and optical bandgap energy of $3.29 \mathrm{eV}$. The well-interconnected spherical nanoparticles with different sizes were examined by Field Emission Scanning Electron Microscopic analysis. The fabricated dye-sensitized solar cell (DSSC) composed of prepared $\mathrm{TiO}_{2}$ microspheres as photoanode exhibited a higher power conversion efficiency (PCE) $(\eta)$ of $5.4 \%$ as compared to commercial P25 with PCE of $3.6 \%$. The higher $\mathrm{J}_{\mathrm{sc}}\left(12.03 \mathrm{~mA} / \mathrm{cm}^{2}\right)$ in the fabricated DSSC due to efficient dye loading capacity and high light-scattering property was also observed.
\end{abstract}

Keywords Titanium dioxide, Microsphere, Dye-sensitized solar cell, Photoanode

\section{Introduction}

According to Nobel laureate Richard Smalley, the big challenge for the next 50 years is mainly in energy conservation and developments towards it to overcome environmental problems [1]. As compared to other renewable energy sources, solar energy proves to be most preferred source due to its continuous and abundant energy supply. The 'Golden Triangle' issues were considered to be an important thing to develop photovoltaic (PV) technology. The issue contains, decreasing the device cost, enhancing the power conversion efficiency and improving the long-term stability [2]. Among three generations of solar cells, third-generation solar cells 
have the ability to rectify the aforementioned issues. Till date, the third-generation solar cells such as perovskite solar cells (PSC) $(\eta=22 \%)$ [3], dye-sensitized solar cells (DSSC) $(\eta=14 \%)$ [4], organic solar cells (OSC) $(\eta=18 \%)$ [5] and quantum dot sensitized solar cells (QDSSC) $(\eta=16 \%)[6]$ were employed due to their superior performance and cost efficiency. More recently DSSCs have received great attention due to their lower cost, easy fabrication process, lightweight and high efficiency. Till date, these cells have shown the maximum power conversion efficiency of $14.3 \%$ and $14.7 \%$ under $100 \mathrm{~mW} / \mathrm{cm}^{2}$ and $50 \mathrm{~mW} / \mathrm{cm}^{2}$ respectively [4]. The cutting edge of research mainly focuses on all DSSCs components such as semiconductor photoanode, highly electrocatalytic counter electrodes, sensitizers and electrolytes. To achieve an excellent performance of photoanodes, larger surface area, fast electron transport kinetics and large light scattering effects are required [7]. $\mathrm{TiO}_{2}$ is a wide bandgap semiconductor metal oxide and is effectively used in versatile applications like photocatalysis [8], Li-ion battery [9], hydrogen production [10], antireflective coatings [11], gas sensors [12], optical filters [13], water splitting [14] and photoelectrochemical solar energy conversion [15]. Due to its unique features such as the high surface area to absorb dye molecules, long-term stability, ease of availability, cost-affordability, non-toxic nature, compatible optical and electronic properties, it is specifically used as photoanode in DSSCs [16]. As compared to other photoanode materials like $\mathrm{ZnO}$ [17], $\mathrm{SnO}_{2}$ [18], $\mathrm{WO}_{3}$ [19], $\mathrm{Nb}_{2} \mathrm{O}_{5}$ [20], $\mathrm{SrTiO}_{2}$ [21], $\mathrm{Zn}_{2} \mathrm{SnO}_{4}$ [22] and $\mathrm{BaSnO}_{3}$ [23], the anatase $\mathrm{TiO}_{2}$ photoanode exhibits highest power conversion efficiency of about 14\% [4]. Various nanostructures like nanotubes [24], nanowires [25], nanofibers [26], hollow spheres [27], microspheres of $\mathrm{TiO}_{2}$ [28-30] were effectively used as photoanode material. Among these aforementioned nanostructures, microspheres were extensively used in DSSC due to their larger surface area, large sphere diameter, superior dye adsorption ability, better light scattering property and efficient interconnection of nanospheres [31]. Several researchers have adopted various techniques to synthesize the microspheres using high temperature hydro/solvothermal treatment [32-33], electrospray preparation [34], low-temperature copolymer synthesis [35], template-free chemically induced self-transformation [36] and electrospun process [37].

In this investigation, the authors have synthesized well-interconnected $\mathrm{TiO}_{2}$ microspheres $\left(\mathrm{TiO}_{2}\right.$ MS) by hydrothermal method and fabricated the DSSC using prepared $\mathrm{TiO}_{2}$ as photoanode. The detailed structural and morphological properties were studied using powder X-ray diffraction (XRD) analysis, Raman spectroscopic analysis and field emission scanning electron microscopic (FESEM) analysis. UV-Vis spectroscopic analysis was carried out to 
study the optical properties and the optical band gap energy was found to be $3.29 \mathrm{eV}$. The fabricated DSSC performance was evaluated and the PCE (5.4\%) from J-V curves, IPCE (56\%) and electron lifetime $\tau(25.24 \mathrm{~ms})$ from EIS were obtained. It was noted that $\mathrm{TiO}_{2} \mathrm{MS}$ based photoanode exhibits superior DSSC performance than P25 based photoanode due to its better light scattering ability and electron transport kinetics.

\section{Experimental section}

\subsection{Materials used}

The following reagents or chemicals were used to prepare $\mathrm{TiO}_{2} \mathrm{MS}$ and fabrication of DSSCs without any further purifications. Fluorine doped tin oxide (FTO, 8 $\Omega$ /square) substrates, Pluronic 123 (99\%), Titanium tetraisopropoxide (99\%), Acetylaceton (99\%), Polyoxyethylene (10) octyl phenyl ether (Triton X-100) were purchased from Sigma Aldrich. Titanium tetrachloride (99\%) was purchased from Spectrochem. Cis - diisothiocyanato-bis(2,2'bipyridyl-4,4'dicarboxylato) ruthenium (II) bis (tetrabutylammonium) (known as N-719 dye), Platisol T/SP, Iodolyte HI-30 were purchased from Solaronix SA, Switzerland, Tetrabutanol Ethanol (99\%), Hydrochloric acid (32\%) and Acetonitrile were purchased from Merck.

\subsection{Synthesis of $\mathrm{TiO}_{2}$ microspheres}

In this typical synthesis procedure, the hydrothermal method was adopted for synthesis of $\mathrm{TiO}_{2}$ $\mathrm{MS}$ and it is as shown in Fig. 1. Initially, $3 \mathrm{~mL}$ of absolute ethanol containing $0.2 \mathrm{~g}$ of pluronic 123 was stirred for 15 minutes and it is termed as solution A for future reference. On the other hand, $1 \mathrm{~mL}$ of titanium tetra isopropoxide was added into solution $\mathrm{B}$ containing $0.7 \mathrm{~mL}$ of concentrated $\mathrm{HCl}$ and stirred for 15 minutes. Then, solution B was successively added into solution A and stirred for 30 minutes. The resultant solution was kept at ambient temperature without any disturbance for 24 hours. After that, $12 \mathrm{~mL}$ of ethanol was added into the resultant mixture and transferred into Teflon-lined stainless steel autoclave for hydrothermal reaction in a hot air oven at $150^{\circ} \mathrm{C}$ for 24 hours. The obtained product was rinsed several times with deionized water and ethanol to remove unwanted impurities. The resulting material was dried at $80^{\circ} \mathrm{C}$ for 24 hours in a vacuum oven. The dried material was annealed at $500^{\circ} \mathrm{C}$ for 1 hour in a muffle furnace.

\subsection{Assembly of DSSC}

Various steps were followed for assembly of DSSC: Initially, $1 \mathrm{~g}$ of prepared $\mathrm{TiO}_{2} \mathrm{MS}$ was mixed with $0.1 \mathrm{~mL}$ of acetylacetone and grounded well with the aid of agate mortar and pestle. 
The grounded products were stirred with a solution containing a 1:1 volume ratio of ethanol and water. $0.4 \mathrm{~mL}$ of Triton- $\mathrm{X}$ was added to the above solution to form a homogenous $\mathrm{TiO}_{2}$ paste. The FTO glass substrate was cleaned with deionized water and ethanol using an ultrasonication bath for 15 minutes. The cleaned FTO substrate was soaked with $0.2 \mathrm{M}$ of aqueous $\mathrm{TiCl}_{4}$ solution at $70^{\circ} \mathrm{C}$ for 30 minutes and rinsed with ethanol and heated at $500^{\circ} \mathrm{C}$ for 30 minutes (Pre- $\mathrm{TiCl}_{4}$ treatment). After that, the doctor blade technique was adopted to coat $\mathrm{TiO}_{2}$ paste on FTO substrate and the coated FTO substrate was sintered at $500^{\circ} \mathrm{C}$ for 1 hour to evaporate the binder materials in the coated films. The thickness of the sample, coated on FTO substrate was found to be $\sim 14 \mu \mathrm{m}$ using a thickness profilometer. The post $\mathrm{TiCl}_{4}$ treatment on sintered $\mathrm{TiO}_{2}$ film was followed like pre $\mathrm{TiCl}_{4}$ treatment process. A similar process was followed to prepare commercial P25 film on FTO substrate. The resultant films were soaked in $0.5 \mathrm{mM}$ of $\mathrm{N} 719$ dye in a $1: 1$ volume ratio of tertbutanol $(10 \mathrm{~mL})$ and acetonitrile $(10 \mathrm{~mL})$ solution for 24 hours under dark conditions. The platinum $(\mathrm{Pt})$ counter electrode was coated on another FTO substrate by doctor blade technique with Platisol T/SP as the platinum precursor and thermally decomposed at $400^{\circ} \mathrm{C}$ for 30 minutes. At last, the dye adsorbed photoanode and Pt counter electrode were sandwiched together. To complete the device fabrication, a small amount of Iodolyte HI-30 as an aqueous electrolyte was injected in-between the two electrodes and the active area of the cell was found to be $0.25 \mathrm{~cm}^{2}$ [38].

\subsection{Characterization techniques}

The crystallographic information of prepared $\mathrm{TiO}_{2} \mathrm{MS}$ was analyzed using a powder X-Ray Diffraction (X'PERT PRO PANALYTICAL, NETHERLANDS) instrument having a $\mathrm{Cu} \mathrm{K} \alpha$ radiation wavelength of $1.5418 \AA$. Micro-Raman measurements were carried out using (RENISHAW InVia Confocal Raman microscope, United Kingdom). Field Emission Scanning Electron Microscope (ZEISS, IIGMA, GHBM, GERMANY) was used to analyze the morphological properties of the prepared $\mathrm{TiO}_{2} \mathrm{MS}$. The optical properties of the prepared material were analyzed using UV-DRS (PerkinElmer, Lambda 35 spectrometer). The current density - voltage characteristics of fabricated DSSC were measured using Keithley digital source meter 2400 under $100 \mathrm{~mW} / \mathrm{cm}^{2}$ illumination coming from a solar simulator (UHE-16 equipped with a 150W Xenon Arc lamp and an AM 1.5 filter, Sciencetech, Canada). The light intensity was calibrated with a standard crystalline silicon solar cell to carry out the J-V measurements. Incident photon-to-current conversion efficiency (IPCE) data were collected in the wavelength from $350 \mathrm{~nm}$ to $800 \mathrm{~nm}$ by using QE system (Enlitech, QE-R). The electrochemical impedance measurement of the fabricated DSSC was analyzed using an 
electrochemical workstation (FRA/VERSASTAT3, V3-500, Princeton Applied Research, USA) under the illumination at open-circuit voltage.

\section{Results and Discussions}

\subsection{X-Ray Diffraction analysis}

Phase identification, crystalline features and average crystallite size of hydrothermally synthesized $\mathrm{TiO}_{2} \mathrm{MS}$ were examined by powder XRD analysis. Fig. 2 demonstrates the powder XRD pattern of synthesized $\mathrm{TiO}_{2}$ MS which possesses a tetragonal crystal structure of an anatase phase with preferred (101) orientation at $2 \theta=25.32^{\circ}$. All the diffraction peaks are wellmatched with JCPDS No: 21-1272 $(\mathrm{a}=\mathrm{b}=3.785, \mathrm{c}=9.513)$ with a crystallographic space group of $I 4_{1} /$ amd. The diffraction peaks located at $25.31^{\circ}, 37.86^{\circ}, 48.07^{\circ}, 53.97^{\circ}, 55.09^{\circ}$, $62.72^{\circ}, 68.85^{\circ}, 70.31^{\circ}$ and $75.15^{\circ}$ were corresponding to (101), (004), (200), (105), (211), (204), (116), (220) and (215) crystal planes respectively. No other additional diffraction peaks corresponding to metallic Ti and other impurity phases like rutile and brookite were observed. Hence, it is evident that synthesized material has pure phase and crystalline nature [28]. The average crystallite size was found to be $18 \mathrm{~nm}$ with the aid of Debye- Scherrer formula, which is as follows

$$
D=\frac{k \lambda}{\beta \cos \theta}
$$

Where ' $\mathrm{D}$ ' is the average crystalline size (nm), ' $\mathrm{k}$ ' is the shape factor which corresponds to 0.9 , ' $\lambda$ ' is the wavelength of $X$-Ray used (1.5418 $\AA$ ), ' $\beta$ ' is the full width at half maximum of prominent diffraction peak (degree) and ' $\theta$ ' is the Bragg's diffraction angle (degree) [39].

\subsection{Raman analysis}

Fig. 3 shows the Raman spectra of synthesized $\mathrm{TiO}_{2} \mathrm{MS}$. The raman scattering peaks obtained at $144 \mathrm{~cm}^{-1}, 197 \mathrm{~cm}^{-1}, 397 \mathrm{~cm}^{-1}, 516 \mathrm{~cm}^{-1}, 639 \mathrm{~cm}^{-1}$ were ascribed to $E_{1 \mathrm{~g}}, \mathrm{E}_{1 \mathrm{~g}}, \mathrm{~B}_{1 \mathrm{~g}}, \mathrm{~A}_{1 \mathrm{~g}}, \mathrm{E}_{1 \mathrm{~g}}$ active vibrational Raman modes. The peaks at $144 \mathrm{~cm}^{-1}, 197 \mathrm{~cm}^{-1}$ and $639 \mathrm{~cm}^{-1}$ corresponds to $\mathrm{E}_{1 \mathrm{~g}}$ mode which is attributed to the symmetric stretching mode of the O-Ti-O bond. The $\mathrm{B}_{1 \mathrm{~g}}$ and $\mathrm{A}_{1 \mathrm{~g}}$ modes of peaks at $397 \mathrm{~cm}^{-1}$ and $516 \mathrm{~cm}^{-1}$ mainly correspond to symmetric and antisymmetric vibration bending modes of O-Ti-O bond respectively. Here, all the observed characteristics peaks belong to the typical anatase $\mathrm{TiO}_{2}$ phase and no other additional phases were observed from Raman spectra which is also in good agreement with XRD results [40-42].

\subsection{UV-Visible spectroscopic analysis}


To study the optical properties of the prepared $\mathrm{TiO}_{2} \mathrm{MS}$, UV-Vis DRS spectroscopic measurements were carried out. Fig. 4 shows diffused reflectance spectra of prepared $\mathrm{TiO}_{2}$ microspheres which was recorded in the wavelength range of 300 to $1100 \mathrm{~nm}$. The prepared $\mathrm{TiO}_{2}$ microspheres exhibit excellent reflectance which will enhance the light scattering property. The optical band gap energy of prepared $\mathrm{TiO}_{2}$ microspheres was determined using Kubelka-Munk function method. The relation is given below.

$$
F(R)=\frac{(1-R)^{2}}{2 R}=\frac{K}{S}
$$

Where $F(R)$ is the Kubelka-Munk function and $R$ is the reflectance. $F(R)$ is directly proportional to absorption coefficient $(\mathrm{K})$ and inversely proportional to scattering coefficient (S) [43]. To estimate the band gap energy, the graph plotted between $h v$ and $(\alpha h F(R))^{2}$ and the band gap energy was found to be $3.29 \mathrm{eV}$ which is in good agreement with bulk $\mathrm{TiO}_{2}$.

\subsection{FESEM analysis}

The surface morphological properties of the prepared material were characterized by field emission scanning microscopic analysis and the FESEM micrograph is shown in Fig. 5. From this micrograph, the $\mathrm{TiO}_{2} \mathrm{MS}$ exhibits smoothly well-defined interconnected nanospheres of various sizes. These microspheres will be the better pathway for electron transport.

\subsection{Photovoltaic performance of the fabricated dye-sensitized solar cell}

Fig. 6 shows the schematic representation of DSSC consisting of semiconductor metal oxide $\left(\mathrm{TiO}_{2} \mathrm{MS}\right)$ coated on FTO substrate sensitized with $\mathrm{N} 719$ ruthenium complex dye for absorbing visible light, $\mathrm{I}_{3}^{-} / \mathrm{I}^{-}$based redox electrolytes for reducing oxidized dye and boosting the redox couple regeneration, a platinum counter electrode for collecting the electrons from the external circuit. According to the principle of DSSC, the voltage generated under the illumination of light radiation corresponds to the difference between the Fermi level of the electron in the binary semiconductor metal oxide and the redox potential of the electrolyte.

Fig. 7 demonstrates the current density - voltage $(\mathrm{J}-\mathrm{V})$ characteristics of fabricated DSSC using prepared $\mathrm{TiO}_{2} \mathrm{MS}$ as photoanode sensitized with $\mathrm{N} 719$ dye for 24 hours. The obtained solar cell parameters such as open-circuit voltage $\left(\mathrm{V}_{\mathrm{oc}}\right)$, short circuit current density $\left(\mathrm{J}_{\mathrm{sc}}\right)$, fill factor (FF) and power conversion efficiency $(\eta)$ are tabulated in Table 1. The fill factor (FF) and power conversion efficiency $(\eta)$ can be expressed as follows: 


$$
\begin{aligned}
& F F=\frac{J_{\max } \times V_{\max }}{J_{S c} \times V_{o c}} \times 100 \\
& \operatorname{PCE}(\eta)=\frac{J_{S C} \times V_{o c} \times F F}{P_{\text {in }}}
\end{aligned}
$$

Where, $V_{\mathrm{oc}}$ and $\mathrm{J}_{\mathrm{sc}}$ are open-circuit voltage $(\mathrm{V})$ and short circuit current density $\left(\mathrm{mA} / \mathrm{cm}^{2}\right)$ of DSSC respectively. $V_{\max }$ and $J_{\max }$ are the maximum voltage and current respectively. $P_{\text {in }}$ is the incident light power $\left(100 \mathrm{~mW} / \mathrm{cm}^{2}\right)$ [41].

Table 1 The photovoltaic parameters of the fabricated device

\begin{tabular}{ccccc}
\hline & $\mathbf{V}_{\text {oc }}(\mathbf{V})$ & $\mathbf{J}_{\mathbf{s c}}\left(\mathbf{m A} / \mathbf{c m}^{\mathbf{2}}\right)$ & FF & PCE (\%) \\
\hline $\mathrm{TiO}_{2} \mathrm{MS}$ & 0.716 & 12.03 & 0.63 & 5.4 \\
$\mathrm{P} 25$ & 0.612 & 09.64 & 0.59 & 3.6
\end{tabular}

The results obtained for the fabricated device exhibit the short circuit current density $\left(\mathrm{J}_{\mathrm{sc}}\right)$ about $12.03 \mathrm{~mA} / \mathrm{cm}^{2}$, open-circuit voltage $\left(\mathrm{V}_{\text {oc }}\right)$ about $0.716 \mathrm{~V}$, fill factor $(\mathrm{FF})$ about 0.63 and the power conversion efficiency $(\eta)$ of $5.4 \%$. At the same time, the device fabricated using P25 exhibits the short circuit current density $\left(\mathrm{J}_{\mathrm{sc}}\right)$ of about $9.64 \mathrm{~mA} / \mathrm{cm}^{2}$, open-circuit voltage $\left(\mathrm{V}_{\mathrm{oc}}\right)$ of $0.612 \mathrm{~V}$, fill factor about 0.59 and the power conversion efficiency of about $(\eta) 3.6 \%$. Basically, the $\mathbf{J}_{\mathrm{sc}}$ of the fabricated DSSC was estimated by the initial number of photogenerated electrons injected into the conduction band of $\mathrm{TiO}_{2}$ photoanode, which are significantly influenced by the light-harvesting performance of the photoanode including the scattering effect of the photoanode structure and the overall dye loading amount [44]. In DSSC, the incident light loss occurs due to the backscattering of incident light in the $\mathrm{FTO} / \mathrm{TiO}_{2}$ interface. The small underlayer consisting of small-sized $\mathrm{TiO}_{2}$ nanoparticles or $\mathrm{TiCl}_{4}$ treatments (pre or post) effectively showed the superior photocurrent density and the power conversion efficiency because of greater effect on electronic transport and causes the downward shift in the band edge [44-45].

Incident photon-to-current conversion efficiency (IPCE) measurements were carried out to understand the performance of photoelectrodes which was shown in Fig 8. The IPCE can be expressed as follows [46]

$$
\begin{aligned}
& I P C E=\left(\frac{h c}{e}\right) \frac{J}{\lambda I_{\text {light }}} \\
& I P C E=1240 \frac{\mathrm{J}}{\lambda I_{\text {light }}}
\end{aligned}
$$


Where $J$ is current density $\left(\mathrm{mA} / \mathrm{cm}^{2}\right), \lambda$ is the incident light wavelength $(\mathrm{nm})$ and $\mathrm{I}_{\text {light }}$ is the measured light intensity $\left(\mathrm{mA} / \mathrm{cm}^{2}\right)$. Here the authors have used wavelength ranging from 350 $\mathrm{nm}$ to $800 \mathrm{~nm}$ and the highest IPCE of about $56 \%$ was obtained at $520 \mathrm{~nm}$. That mainly attributes to superior light scattering deriving from its characteristic photonic reflection effect which results in the higher $\mathrm{J}_{\mathrm{sc}}$ in the fabricated device [44].

In DSSC, the electrochemical impedance spectroscopic analysis was used to understand the detailed charge transport and recombination kinetics of electrochemical properties. Fig 9 shows the Nyquist plot of a fabricated device which exhibit three semicircles corresponding to the diffusion of $\mathrm{I}_{3}^{-} / \mathrm{I}^{-}$electrolyte in lower frequency region, charge transport at Pt/electrolyte interface in higher frequency region and the electron transport kinetics at dye/ $\mathrm{TiO}_{2} /$ electrolyte interface in middle-frequency region [47]. Fig 10 demonstrates the corresponding bode plot of the fabricated device and the maximum mid-frequency was observed at $6.31 \mathrm{~Hz}$. The electron lifetime can be found to be $25.24 \mathrm{~ms}$ with the aid of the following relation and all EIS parameters are tabulated in Table 2.

$$
\tau_{e}=\frac{1}{2 \pi f_{\max }}
$$

Where $\mathrm{f}_{\max }$ is the peak frequency obtained from the bode plot [47].

Table 2 EIS parameters of the fabricated device

\begin{tabular}{ccccccc}
\hline Sample & $\mathbf{R}_{\mathbf{s}}(\mathbf{\Omega})$ & $\mathbf{R}_{\mathbf{c t 1}}(\mathbf{\Omega})$ & $\mathbf{R}_{\mathbf{c t 2}}(\mathbf{\Omega})$ & $\mathbf{R}_{\mathbf{c t 3}}(\mathbf{\Omega})$ & $\mathbf{f}_{\mathbf{m a x}}(\mathbf{H z})$ & $\boldsymbol{\tau}_{\mathbf{e}}(\mathbf{m s})$ \\
\hline $\mathrm{TiO}_{2} \mathrm{MS}$ & 11.12 & 01.82 & 08.05 & 04.66 & 6.31 & 25.24 \\
\hline
\end{tabular}

\section{Conclusion}

The $\mathrm{TiO}_{2}$ microspheres were successfully synthesized using a one-step hydrothermal route. The pure anatase phase formation of $\mathrm{TiO}_{2} \mathrm{MS}$ was confirmed with the aid of XRD and Raman analysis. The average crystallite size was found to be $18 \mathrm{~nm}$ by adopting the Debye Scherrer formula. The UV-Vis DRS results depict better reflectance and the optical bandgap energy was found to be $3.29 \mathrm{eV}$ using Kubelka-Munk function plot. The DSSC was fabricated with the structure of $\mathrm{FTO} / \mathrm{TiO}_{2} \mathrm{MS}$ - dye/redox couple electrolyte/Pt/FTO and its efficiency was estimated under standard one sun illumination $\left(100 \mathrm{~mW} / \mathrm{cm}^{2}\right)$. The photoanode made of $\mathrm{TiO}_{2}$ MS exhibits excellent power conversion efficiency of 5.4\%. The improved PCE and $\mathrm{J}_{\mathrm{sc}}$ could be due to superior light scattering properties, electron transport properties and pre-and posttreatment of $\mathrm{TiCl}_{4}$ in Photoanode. 


\section{Acknowledgment}

The authors gratefully acknowledge Sathyabama Institute of Science and Technology for providing access to their Raman and FESEM facilities.

\section{Funding}

SSN Trust (partially)

\section{Conflicts of interest}

There are no conflicts to declare

\section{Availability of data and material}

Available data is transparent

\section{References}

1. M. S. Ahmad, A. K. Pandey, N. A. Rahim, Renew. Sust 77, 89 (2019)

2. S. Mozaffaria, M. R. Nateghib, M. B. Zarandi, Renew. Sust 71, 675 (2017)

3. W. S. Yang, B. W. Park, E. H. Jung, N.J. Jeon, Y. C. Kim, D. U. Lee, S. S. Shin, J. Seo, E. K. Kim, J. H. Noh, S. I. Seok, Science 356, 1376 (2018)

4. K. Kakiage, Y. Aoyama, T. Yano, K. Oya, J. Fujisawab, M. Hanaya, ChemComm 88, 15894 (2015).

5. Q. Liu, Y. Jiang, K. Jin, J. Qin, J. Xu, W. Li, J. Xiong, J. Liu, Z. Xiao, K. Sun, S. Yang, X. Zhang, L. Ding, Sci. Bull. 65, 272 (2020)

6. M. Hao, Y. Bai, S. Zeiske, L. Ren, J. Liu, Y. Yuan, N. Zarrabi, N. Cheng, M. Ghasemi, P. Chen, M. Lyu, D. He, J. H. Yun, Y. Du, Y. Wang, S. Ding, A. Armin, P. Meredith, G.Liu, H. M. Cheng, L. Wang, Nat. Energy 5, 79 (2020)

7. X. Sun, Y. Liu, Q. Tai, B. Chen, T. Peng, N. Huang, S. Xu, T. Peng, X. Z. Zhao, J. Phys. Chem. C 116, 11859 (2012)

8. A. Wold, Chem. Mater 5, 280 (1993)

9. H. G. Jung, S. W. Oh, J. Ce, N. Jayaprakash, Y. K. Sun, Electrochem. Commun 11, 756 (2009)

10. B. Liu, L. M. Liu, X. F. Lang, H. Y. Wang, X. W. (David) Lou, E. S. Aydil, Energy Environ. Sci. 7, 2592 (2014)

11. B. S. Richards, Sol. Energy Mater. Sol. Cells 79, 369 (2003) 
12. B. Karunagaran, P. Uthirakumar, S.J. Chung, S. Velumani, E.-K. Suh, Mater. Charact. $58,680(2007)$

13. M. Kitui, M. M. Mwamburi, F. Gaitho, C. M. Maghanga, Int. J. Thin Fil. Sci. Tec. 4, $17(2015)$

14. S. U. M. Khan, M. Al-Shahry, W. B. I. Jr, science 297, 2243 (2002)

15. B. O’Regan, M. Gratzel, nature 353, 737 (1991)

16. Y-Y. Yu, B-X. Lei, M-L. Xie, G-L. Huang, W. Sun, Z-F. Sun, Adv Powder Technol $26,1072(2015)$

17. S. S. Kanmani, K. Ramachandran, J Mater Sci 48, 2076 (2013)

18. E. Ramasamy, Jinwoo Lee, J. Phys. Chem. C 114, 22032 (2010)

19. H. Zheng, Y. Tachibana, K. K. zadeh, Langmuir 26, 19148 (2010)

20. J. Z. Ou, R. A. Rani, M. H. Ham, M. R. Field, Y. Zhang, H. Zheng, P. Reece, S. Zhuiykov, S. Sriram, M. Bhaskaran, R. B. Kaner, K.K. zadeh, ACS nano 6, 4045 (2012)

21. P. Jayabal, V. Sasirekha, J. Mayandi, K. Jeganathan, V. Ramakrishnan, J. Alloys. Compd 586, 456 (2014)

22. J. Chen, L. Lu, W. Wang, J. Phys. Chem. C 116, 10841 (2012)

23. N. Rajamanickam, P. Soundarrajan, S.M. Senthil Kumar, K. Jayakumar, K. Ramachandran, Electrochim. Acta 296, 771 (2019)

24. M. R. Venkatraman, N. Muthukumarasamy, P. Balraju, P. Selvakumar, V. Dhayalan, P. Arivalagan, Int. J. Hydrog. Energy 45, 15441 (2020)

25. X. Feng, K. Zhu, A. J. Frank, C. A. Grimes, T. E. Mallouk, Angewandte Chemie 124, $2781(2012)$

26. M. S. Mahmoud, M. S. Akhtar, I. M. A. Mohamed, R. Hamdan, Y. A. Dakka, N. A.M. Barakat, Mater. Lett 225, 77 (2018)

27. X. Y. Ye, Y. H. Gu, H. Chen, Y. F. Cao, Y.Y. Liu, B. X. Lei, W. Sun, Z. F. Sun, Adv Powder Technol 30, 2408 (2019)

28. Z. Q. Li, Y. P. Que, L.E Mo, W.C. Chen, Y. Ding, Y. Mei Ma, L. Jiang, L. H. Hu, S. Y. Dai, Appl. Mater. Interfaces 7, 10928 (2015)

29. J. D. Peng, C. M. Tseng, R. Vittal, K. C. Ho, Nano energy 22, 136 (2016)

30. P. Ilaiyaraja, T. K. Das, P. S. V. Mocherla, C. Sudakar, Sol. Energy Mater. Sol. Cells $169,86(2017)$

31. H. Tao, W. Chen, J. Wang, W. Ke, J. Wan, J. Wu, G. Fang, Electrochim. Acta 13717 (2014) 
32. X. Miao, K. Pan, Y. Liao, W. Zhou, Q. Pan, G. Tian, G. Wang, J. Mater. Chem 1, 9853 (2013)

33. F. Sauvage, D. Chen, P. Comte, F. Huang, L. P. Heiniger, Y. B. Cheng, R. A. Caruso, M. Graetzel, Acs Nano 8, 4420 (2010)

34. D. Hwang, H. Lee, S. Y. Jang, S. M. Jo, D. Kim, Y. Seo, D. Y. Kim, Appl. Mater. Interfaces 3, 2719 (2011)

35. Y. Zhou, E. Y. Ding, W. D. Li, Mater. Lett 61, 5050 (2007)

36. J. Yu, J. Zhang, Dalton Trans 25, 5860 (2010)

37. G. Zhu, L. Pan, J. Yang, X. Liu, H. Sun, Z. Sun, J. Mater. Chem 22, 24326 (2012)

38. R. Govindaraj, N. Santhosh, M. S. Pandian, P. Ramasamy, Appl. Surf. Sci. 449, 166 (2018)

39. S. S. Kanmani, N. Rajkumar, K. Ramachandran, Int. J. Nanosci 10, 227 (2011)

40. M.R. Venkatraman, N. Muthukumarasamy, S. Agilan, V. Asokan, D. Velauthapillai, Mater. Res. Bull. 97, 351 (2018)

41. R. Govindaraj, N. Santhosh, M. S. Pandian, P. Ramasamy, M. Sumita, J. Mater. Sci.: Mater. Electron. 29, 3736 (2018)

42. X. Tao, P. Ruan, X. Zhang, H. Sun, X. Zhou, Nanoscale 8, 3539 (2015)

43. T. Amutha, M. Rameshbabu, S. S. Florence, N. Senthilkumar, I.V. Potheher, K. Prabha, Res. Chem. Intermed. 45, 1929 (2019)

44. C. Ma, L. Wang, Z. Guo, Y. Lv, W. Chen, Hui Ming, P. Ma, J. Wang, Colloids Surf. A 538, $94(2018)$

45. S. D. Liu, Y. K. Ren, Z. Zhou, W. C. Chen, Z. Q. Li, F. L. Guo, Li. E. Mo, J.H. Wu, L. H. Hu, S. Y. Dai, Adv Powder Technol 329, 225 (2019)

46. N. Rajamanickam, K. Ramachandran, J. Colloid Interface Sci. 580, 407 (2020)

47. Z. Ge, C. Wang, Z. Chen, T. Wang, T. Chen, R. Shi, S. Yu, J. Liu, Mater. Res. Bull. $135,111148(2021)$ 


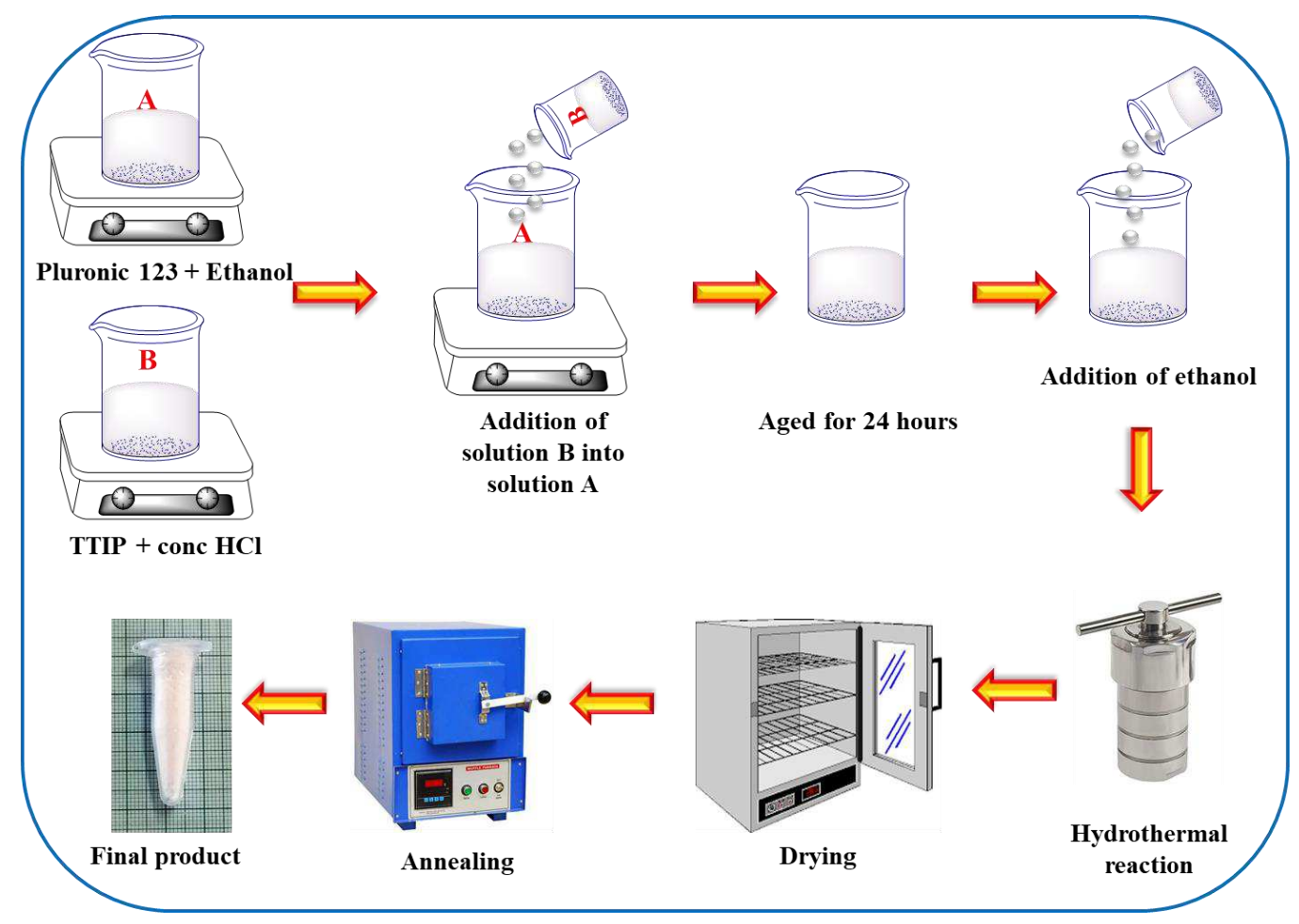

Fig. 1 Schematic representation for the synthesis of $\mathrm{TiO}_{2} \mathrm{MS}$ 


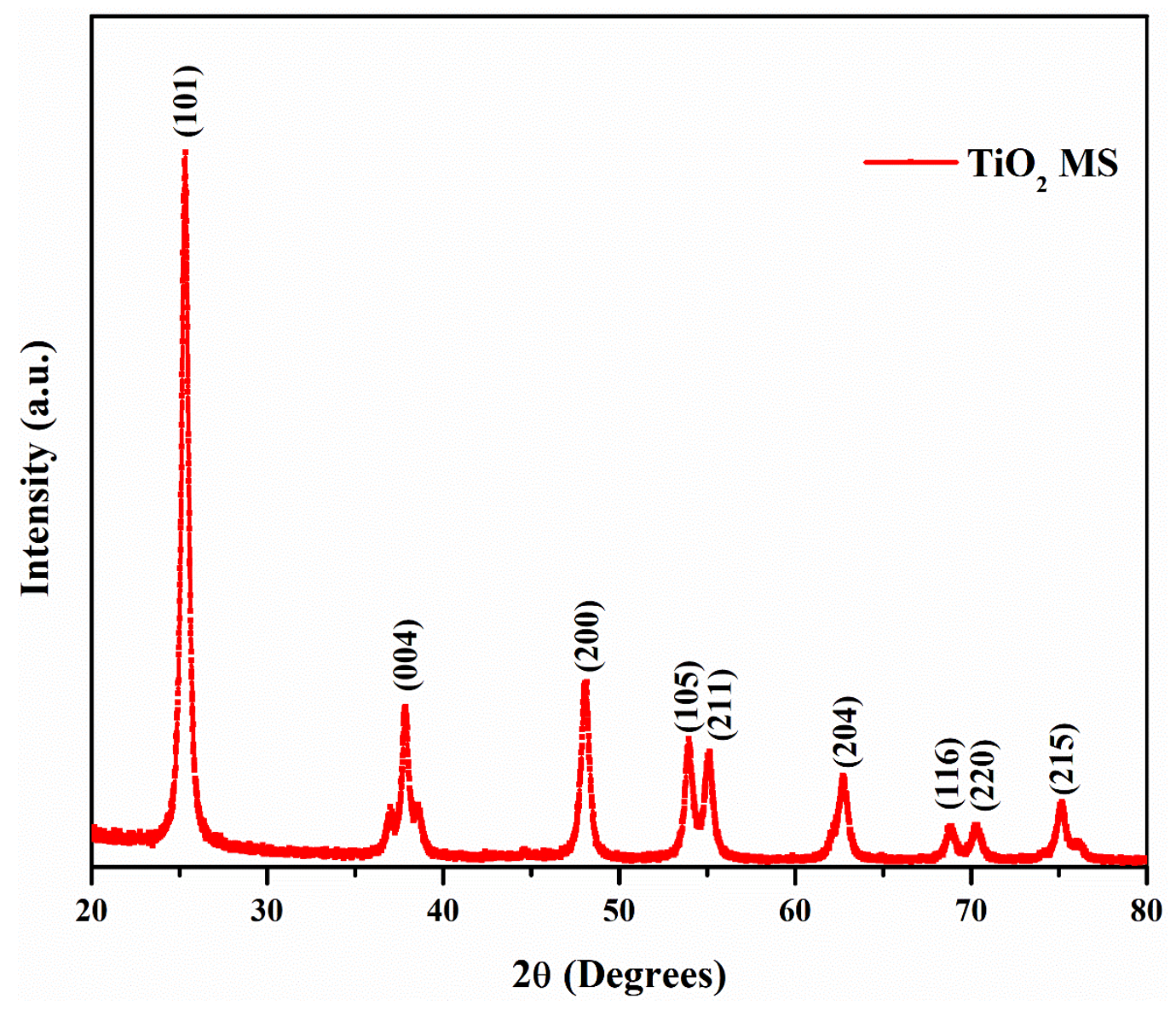

Fig. 2 Powder XRD pattern of $\mathrm{TiO}_{2} \mathrm{MS}$ 


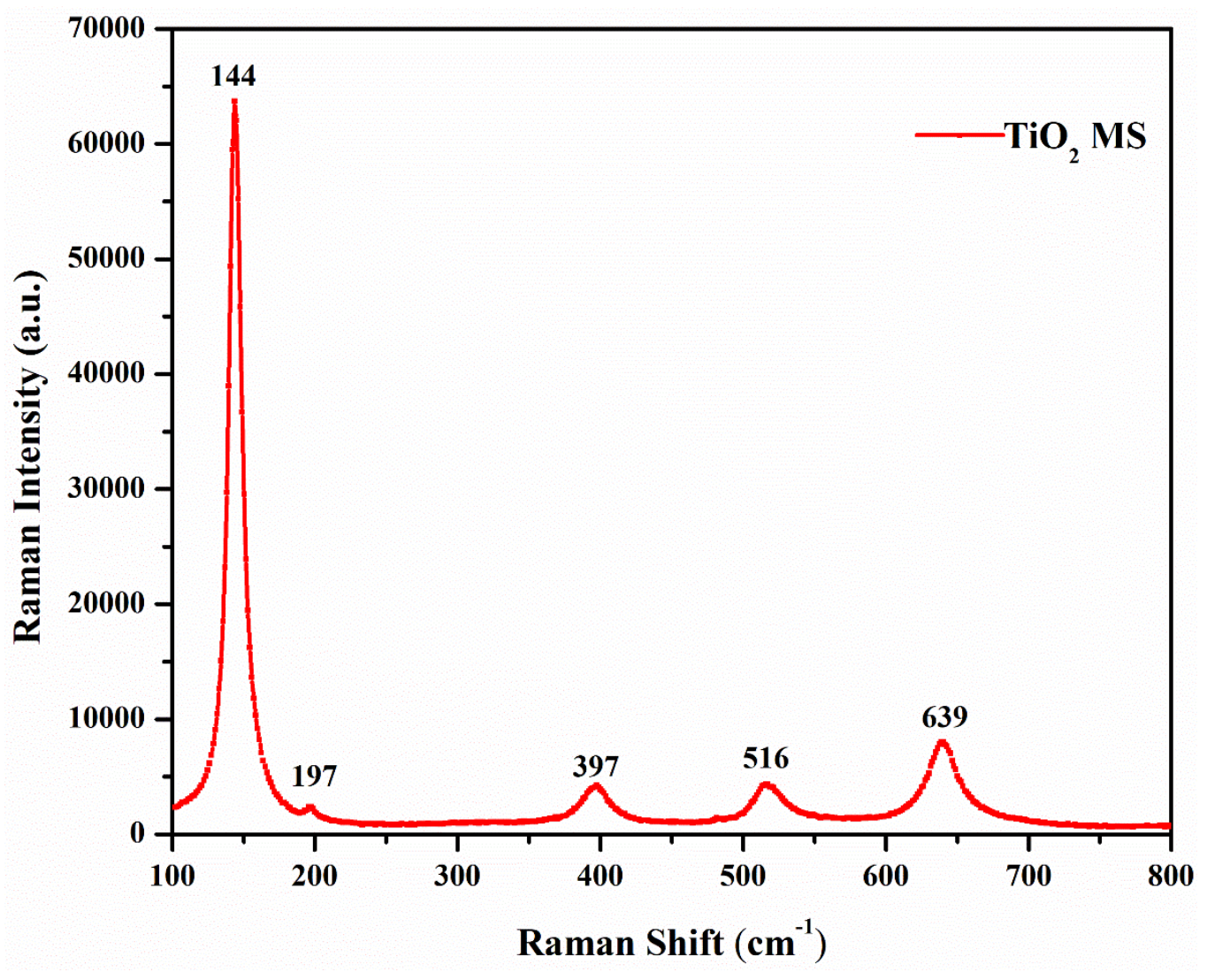

Fig. 3 Raman spectrum of $\mathrm{TiO}_{2} \mathrm{MS}$ 


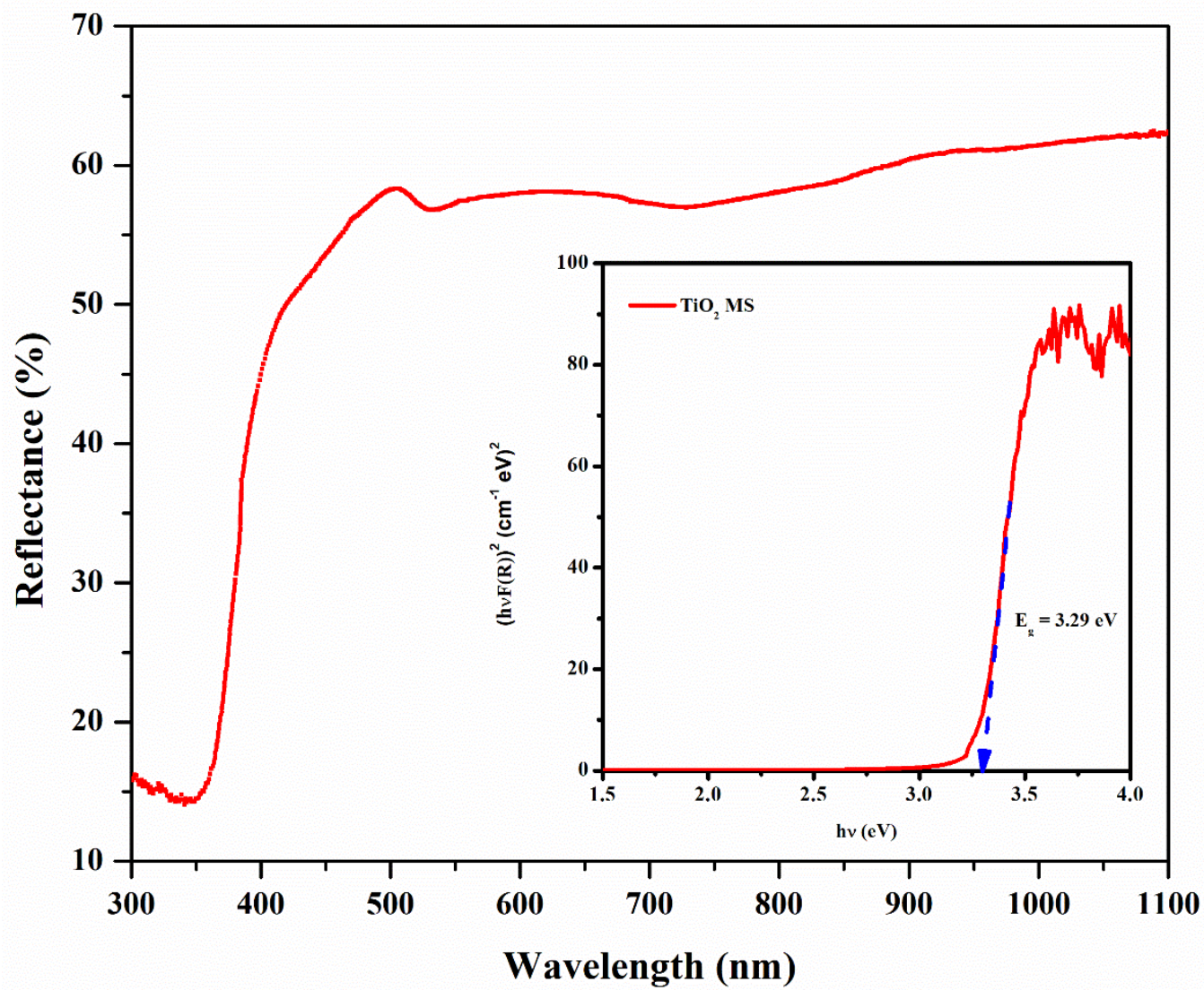

Fig. 4 UV-Vis DRS spectrum of $\mathrm{TiO}_{2} \mathrm{MS}$ and inset shows the Kubelka-Munk function plot 


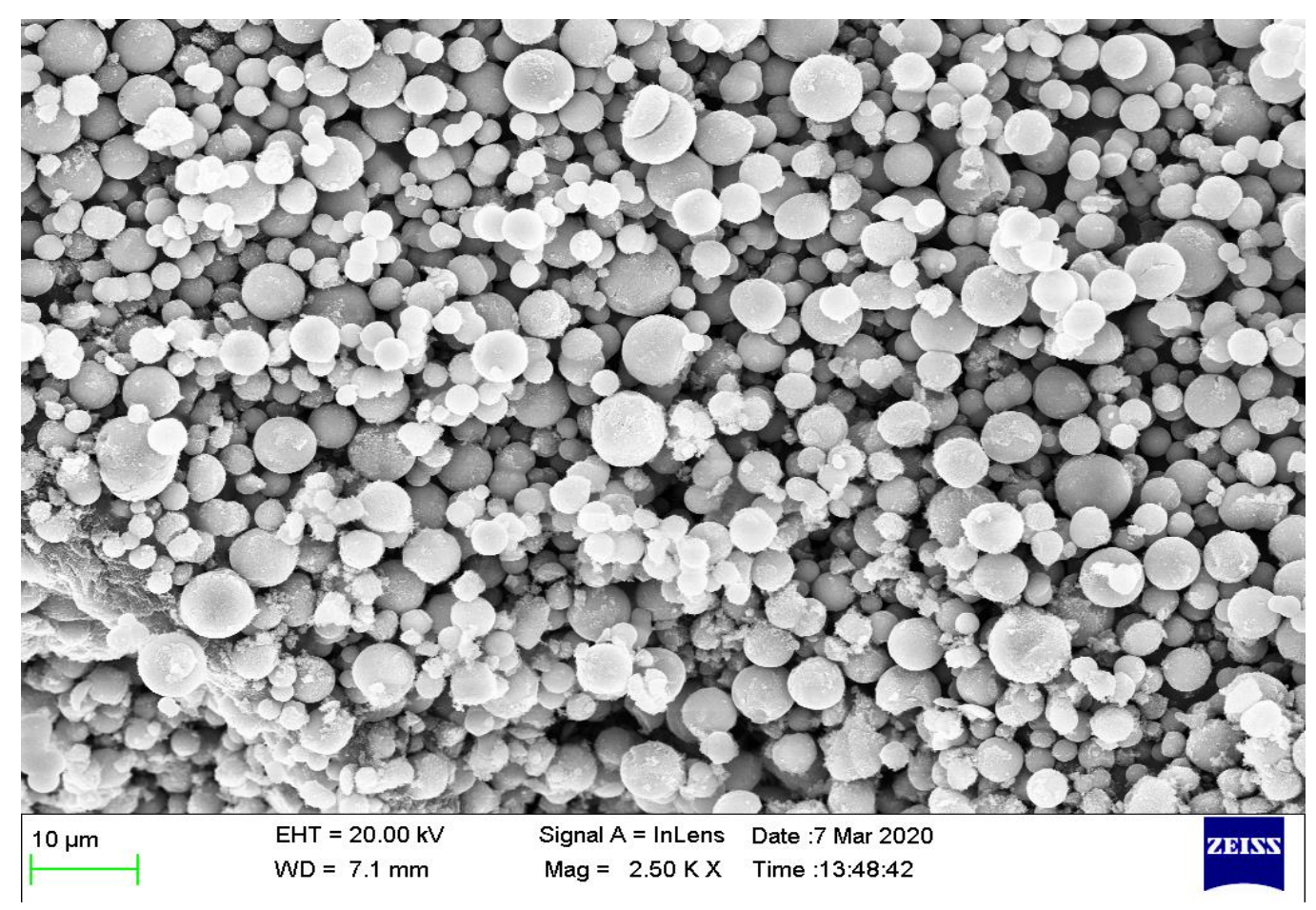

Fig. 5 FESEM micrograph of $\mathrm{TiO}_{2} \mathrm{MS}$ 


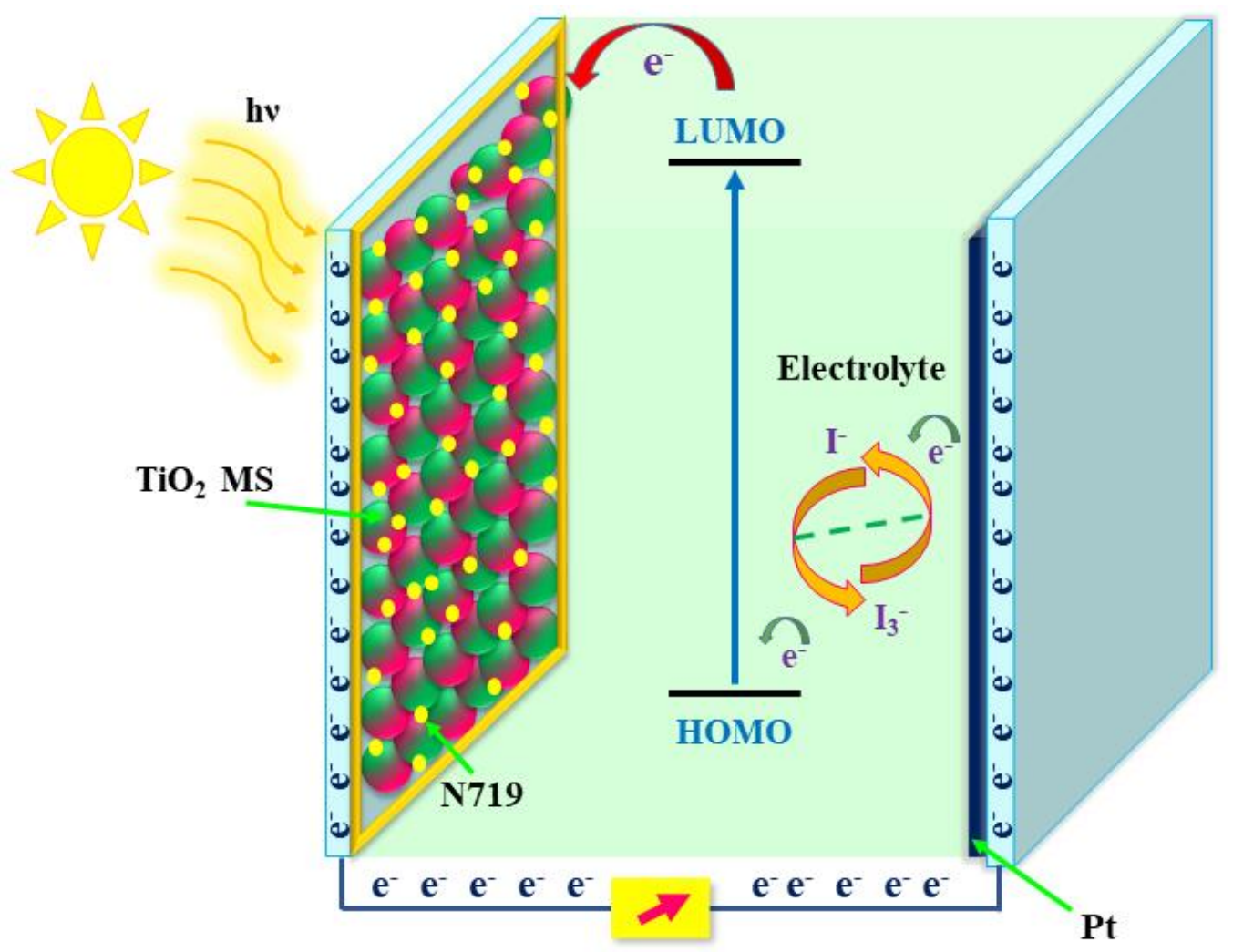

Fig. 6 Schematic diagram of DSSC 


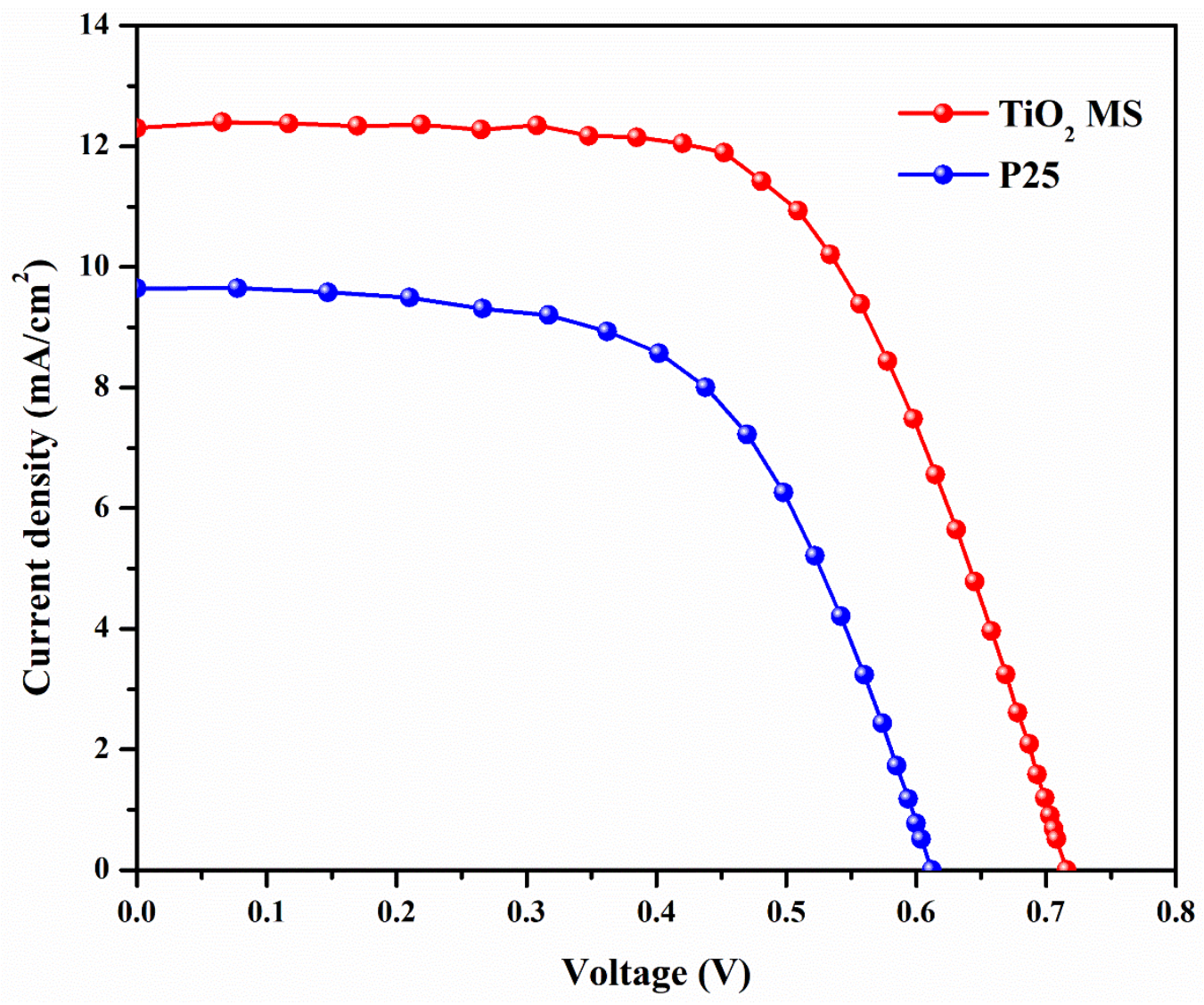

Fig. 7 Current density - voltage curves of $\mathrm{TiO}_{2} \mathrm{MS}$ and commercial P25 based DSSCs 


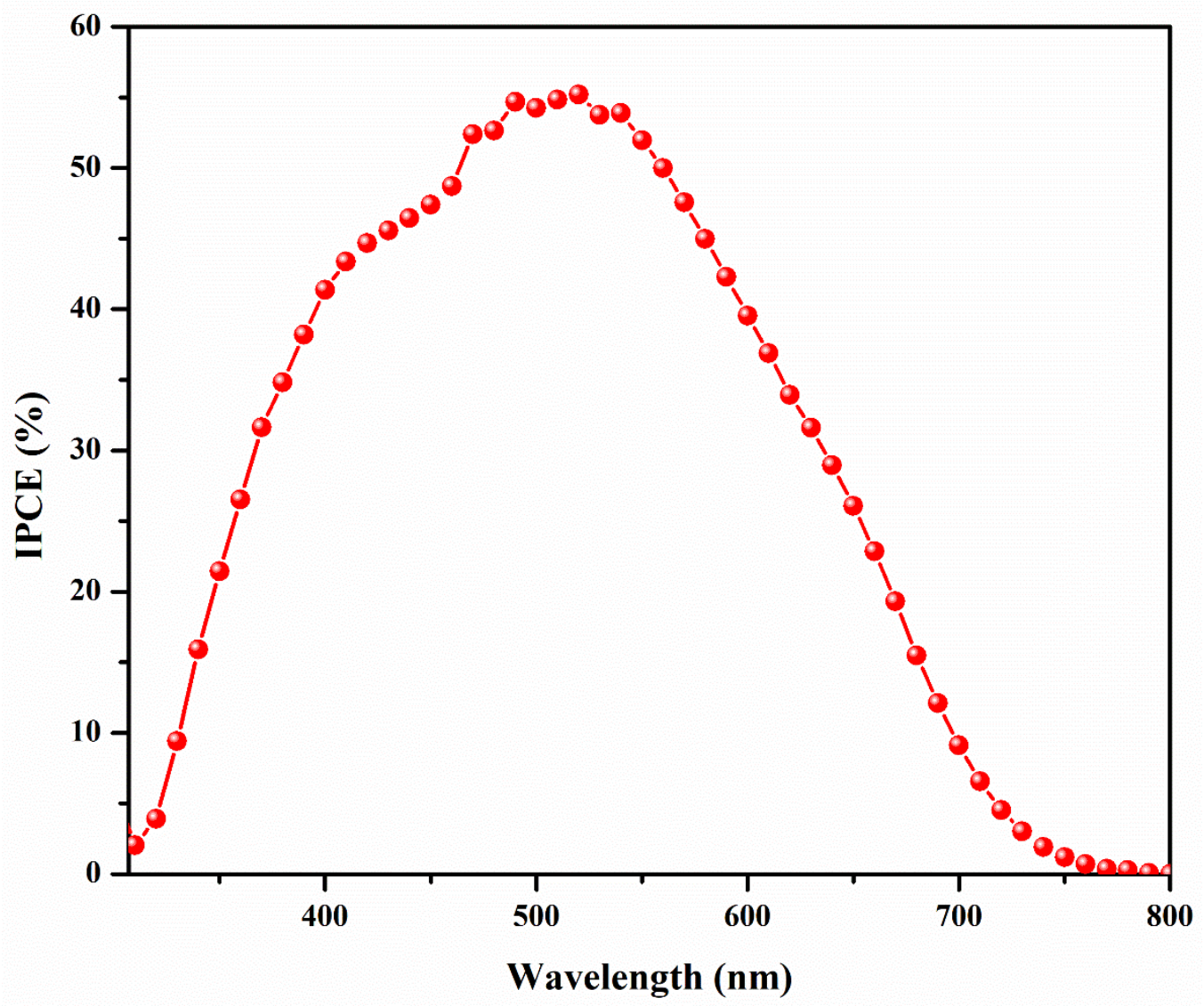

Fig. 8 Incident photon-to-current conversion efficiency (IPCE) spectra of $\mathrm{TiO}_{2} \mathrm{MS}$ based DSSC 


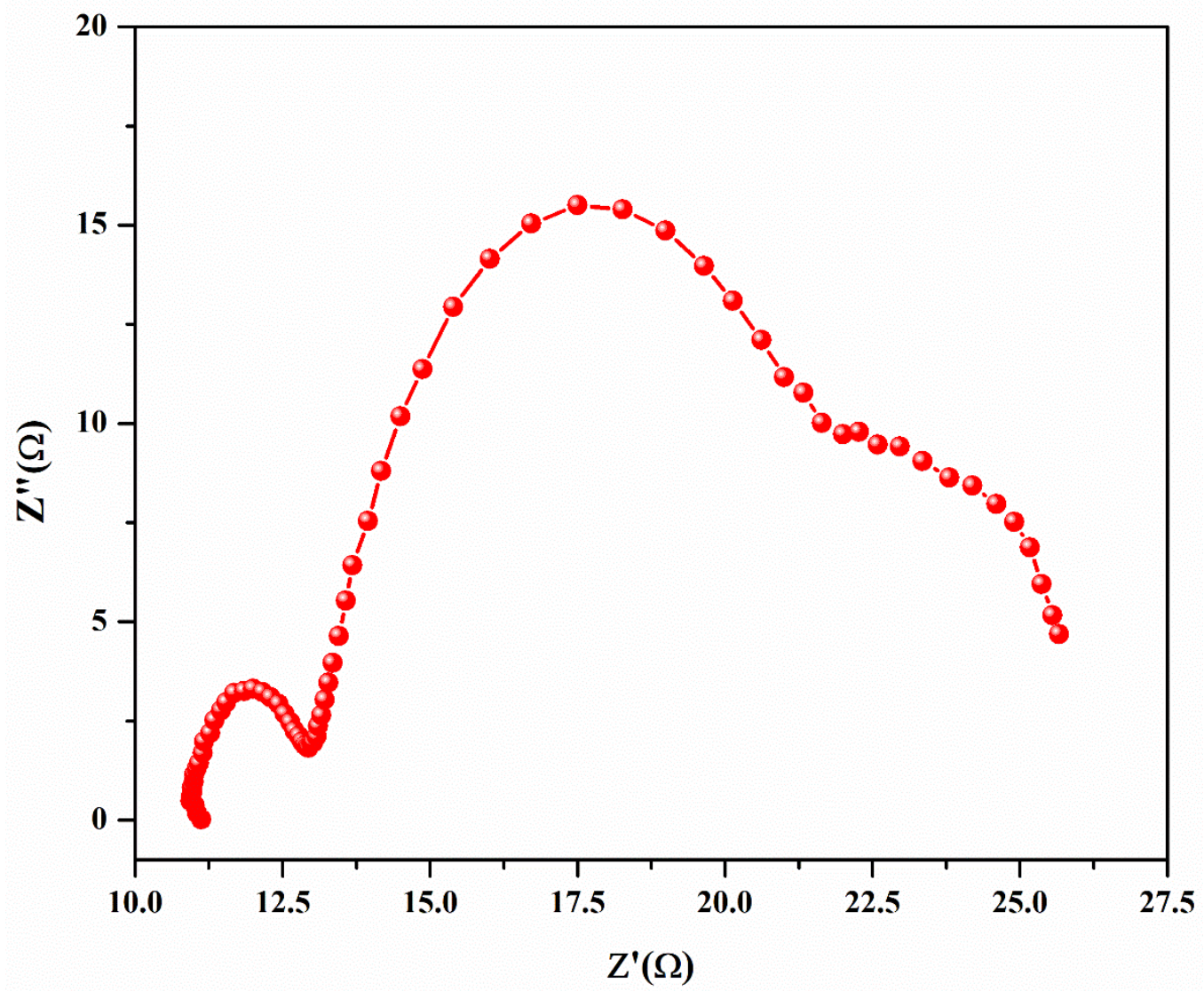

Fig. 9 Nyquist plot for $\mathrm{TiO}_{2}$ MS-based DSSC 


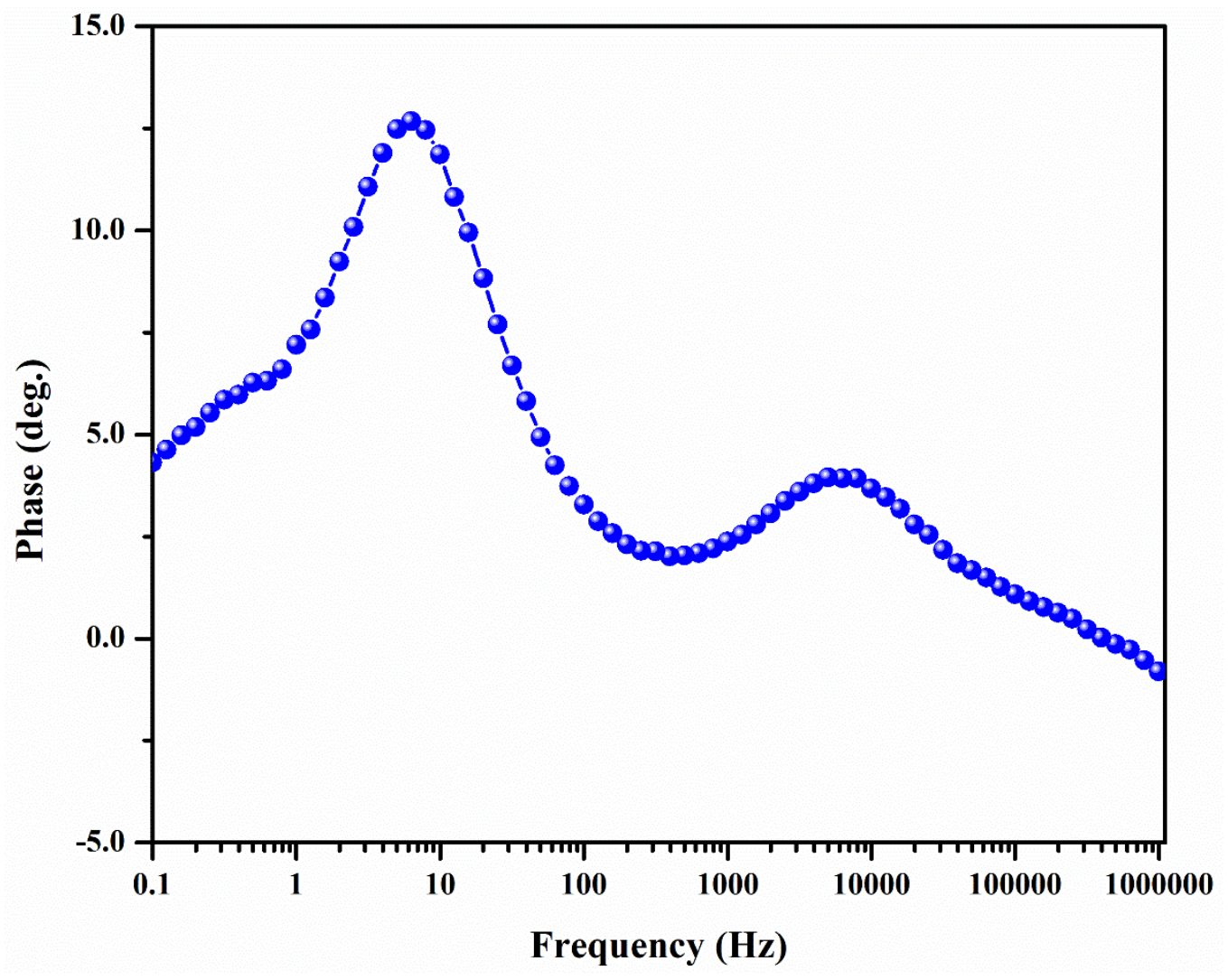

Fig. 10 Bode plot for $\mathrm{TiO}_{2}$ MS-based DSSC 
Figures

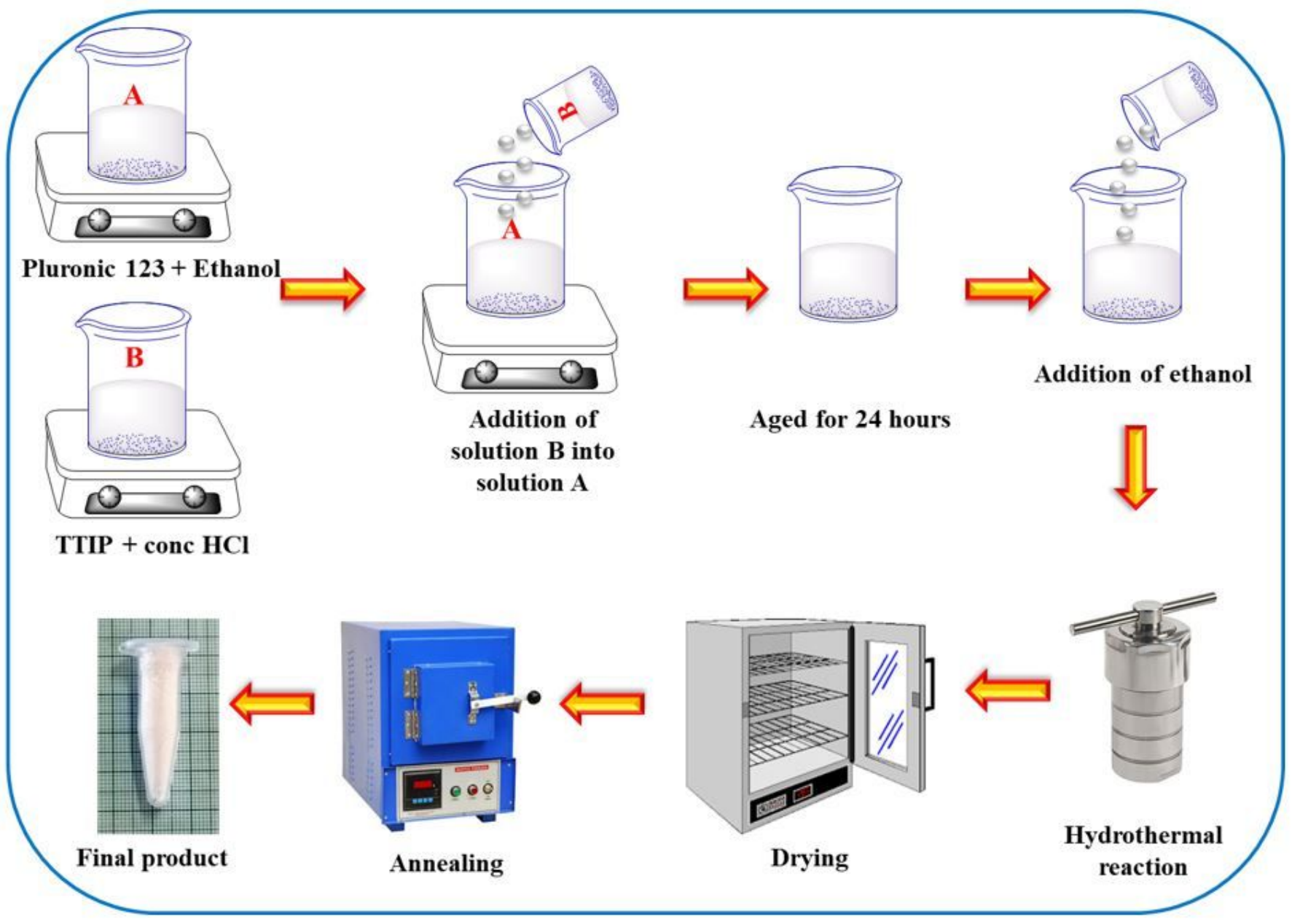

Figure 1

Schematic representation for the synthesis of TiO2 MS 


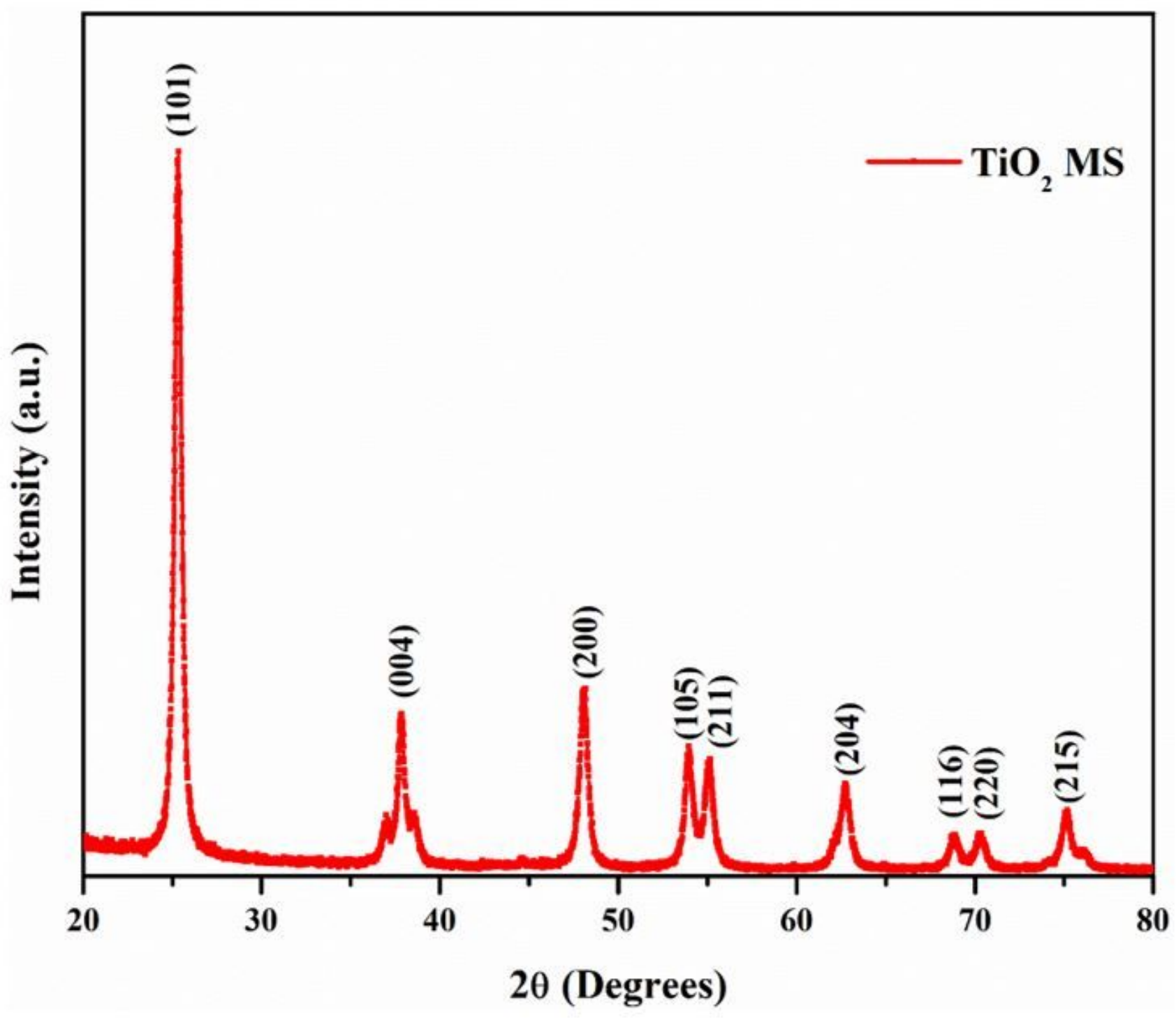

Figure 2

Powder XRD pattern of TiO2 MS 


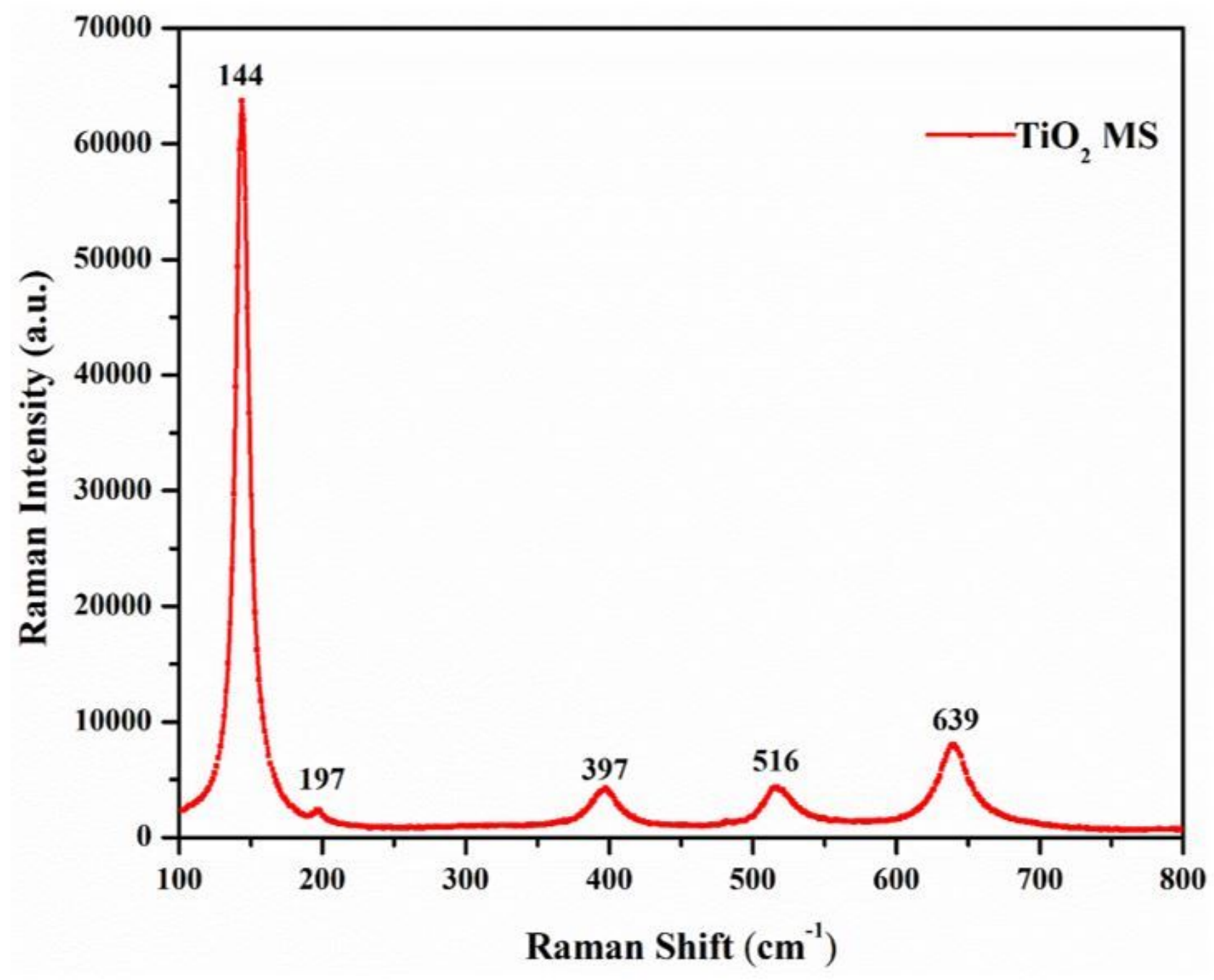

Figure 3

Raman spectrum of $\mathrm{TiO} 2 \mathrm{MS}$ 


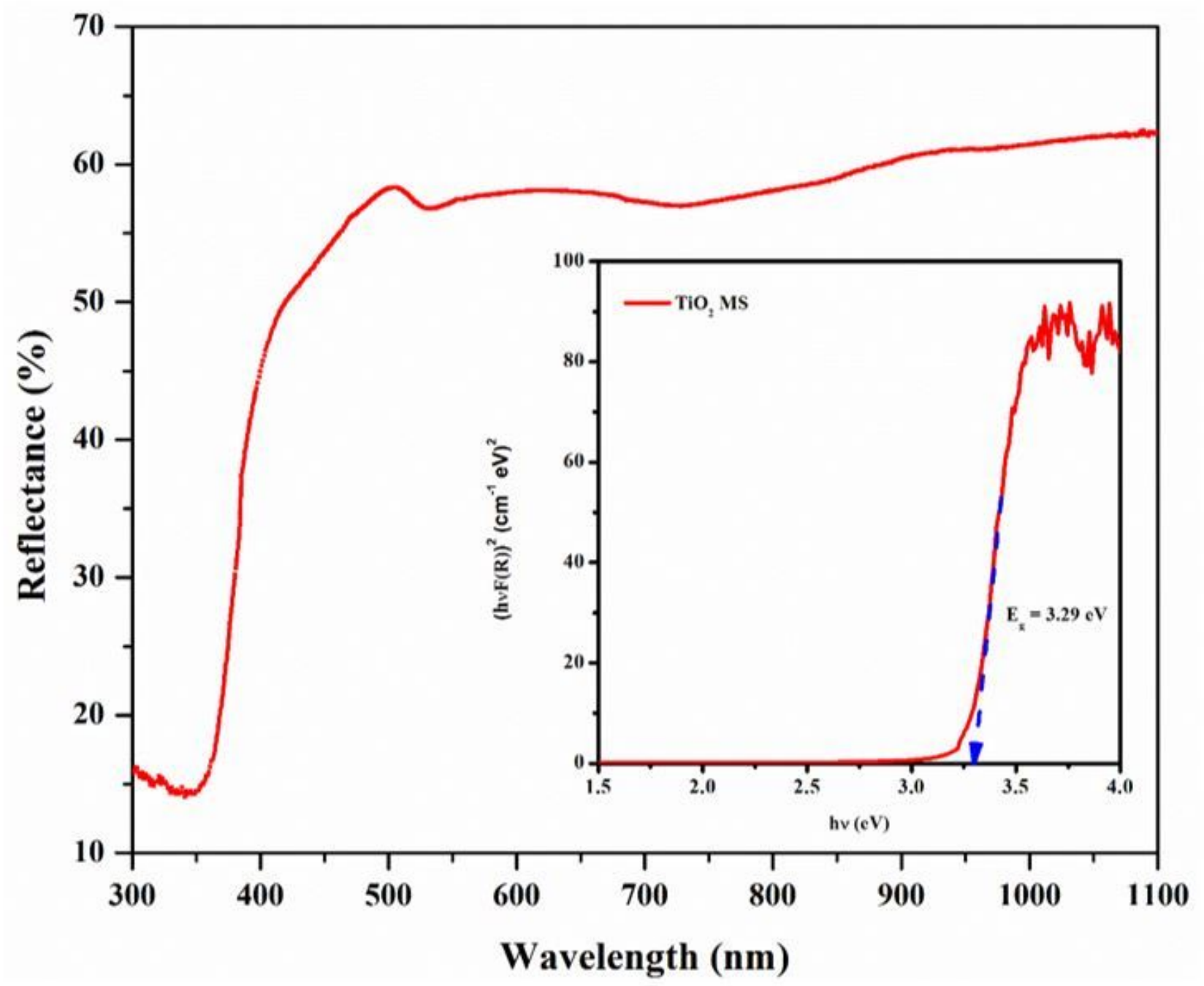

Figure 4

UV-Vis DRS spectrum of TiO2 MS and inset shows the Kubelka-Munk function plot 


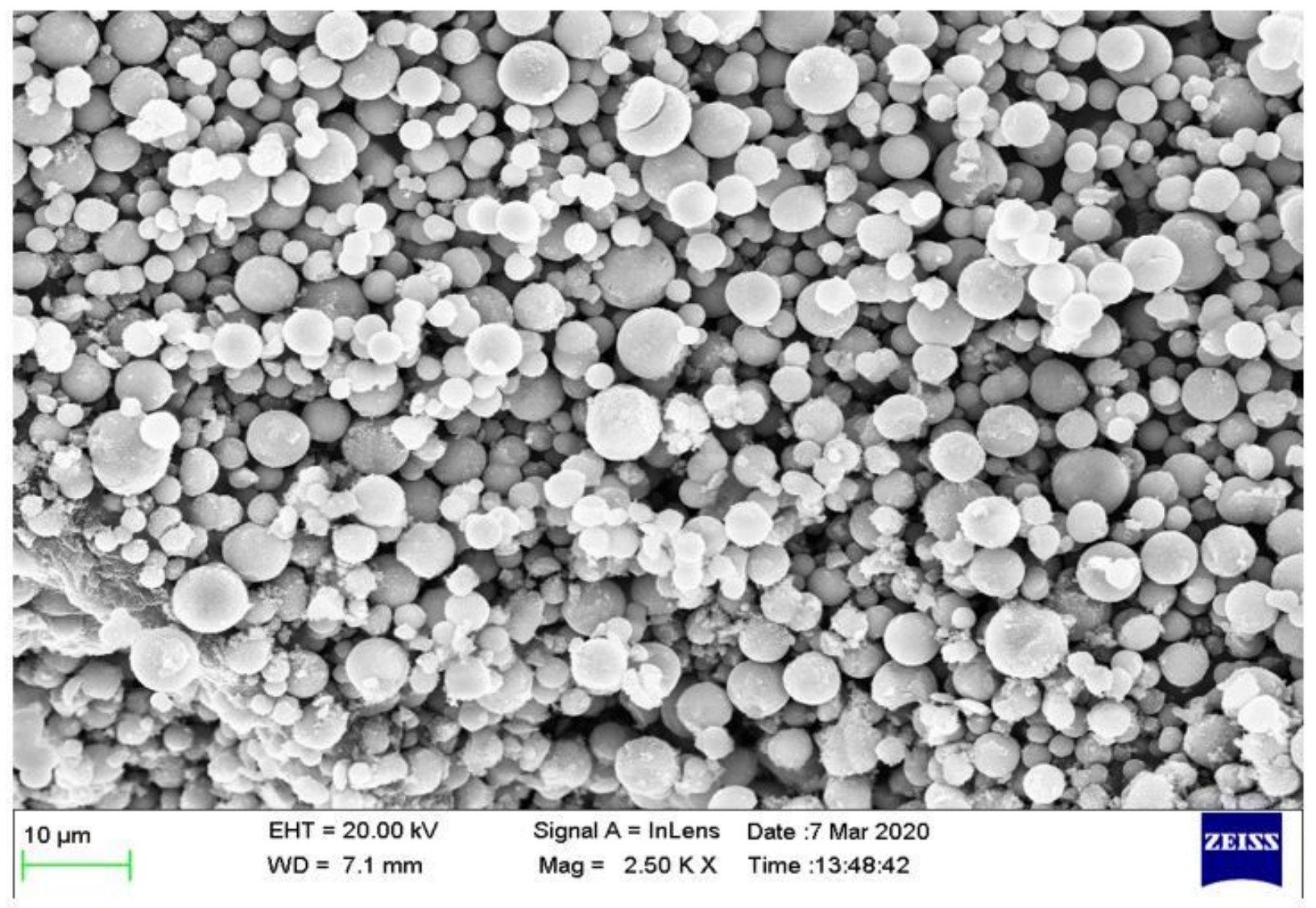

Figure 5

FESEM micrograph of TiO2 MS 


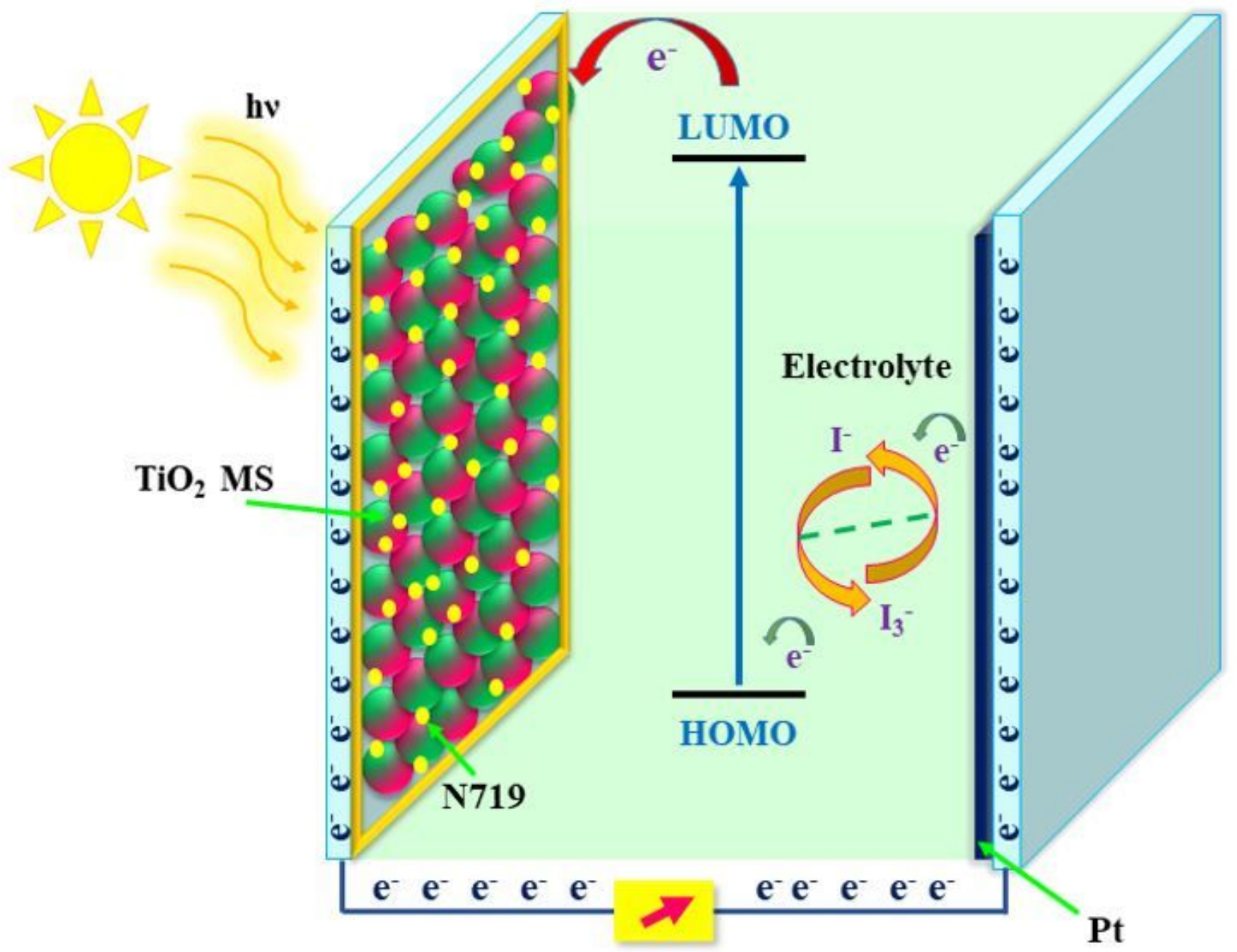

Figure 6

Schematic diagram of DSSC 


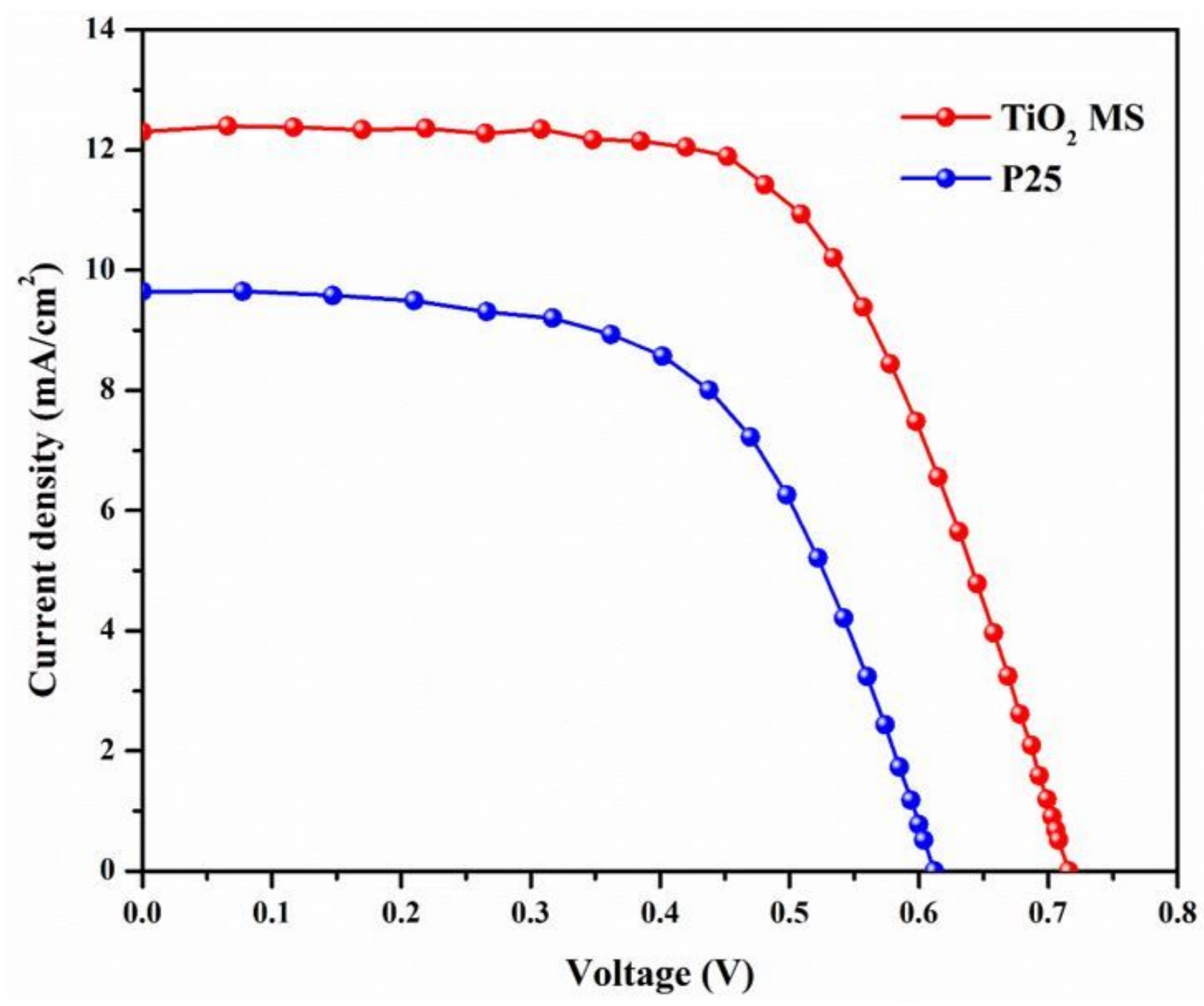

Figure 7

Current density - voltage curves of TiO2 MS and commercial P25 based DSSCs 


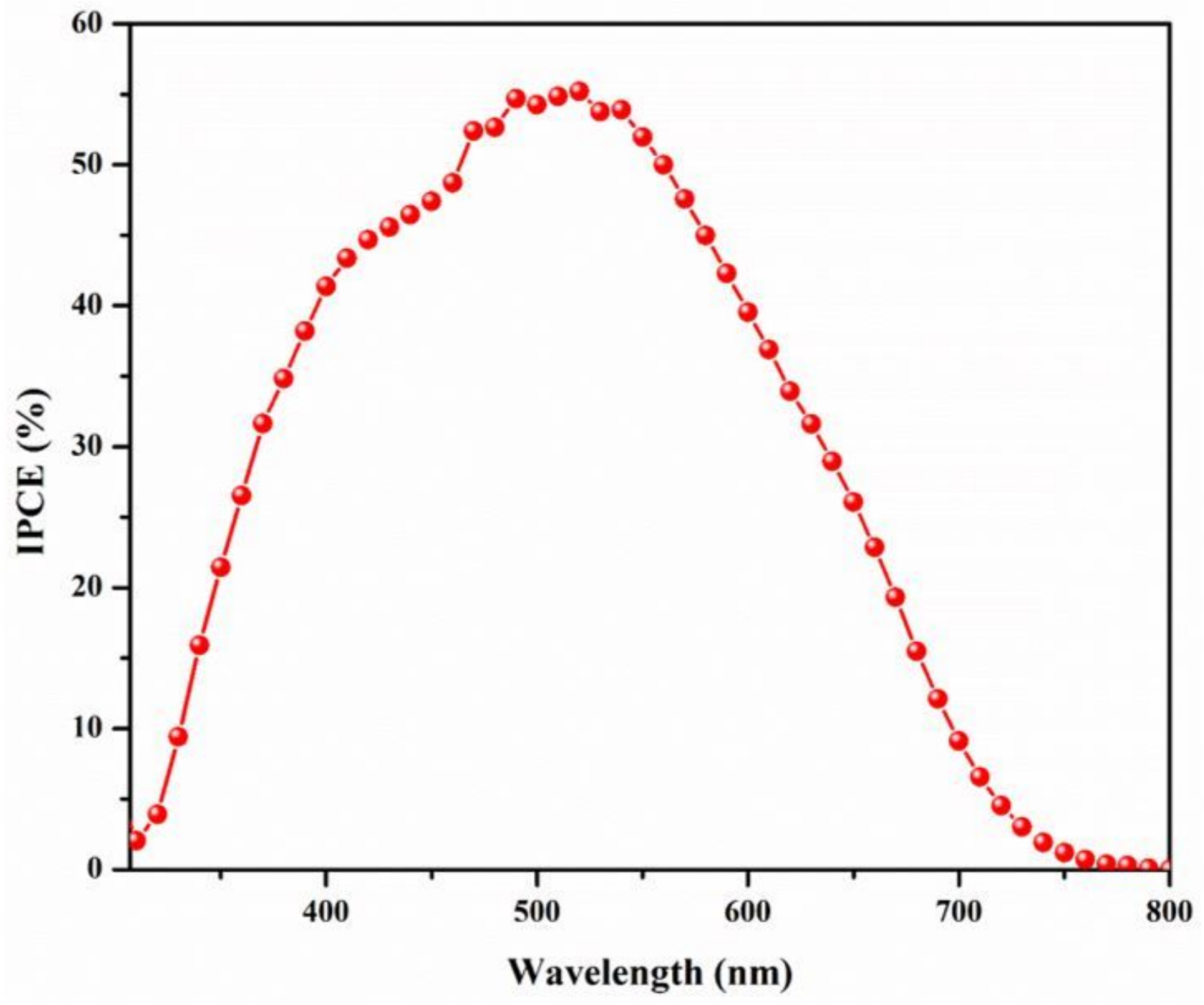

Figure 8

Incident photon-to-current conversion efficiency (IPCE) spectra of TiO2 MS-based DSSC 


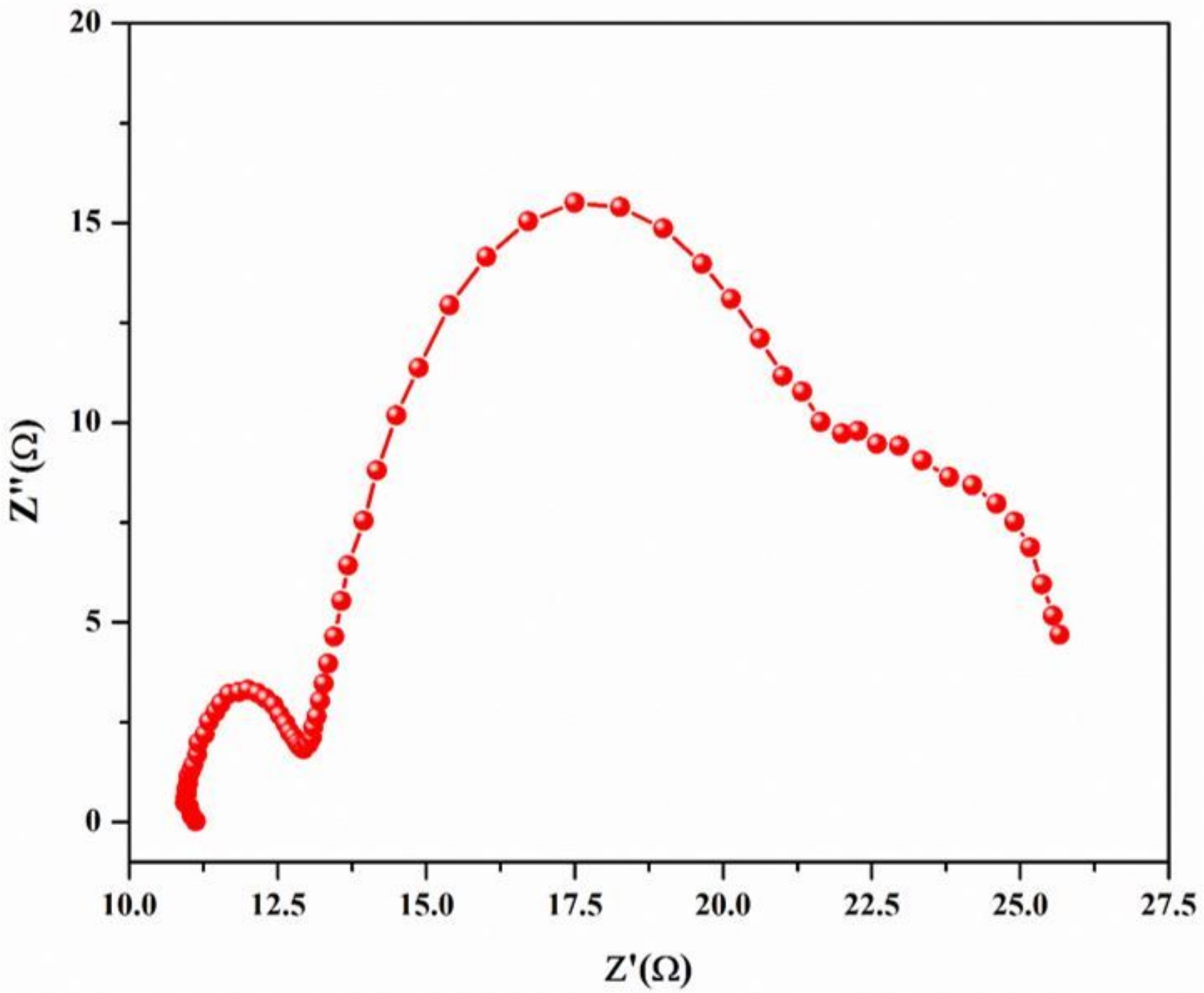

Figure 9

Nyquist plot for TiO2 MS-based DSSC 


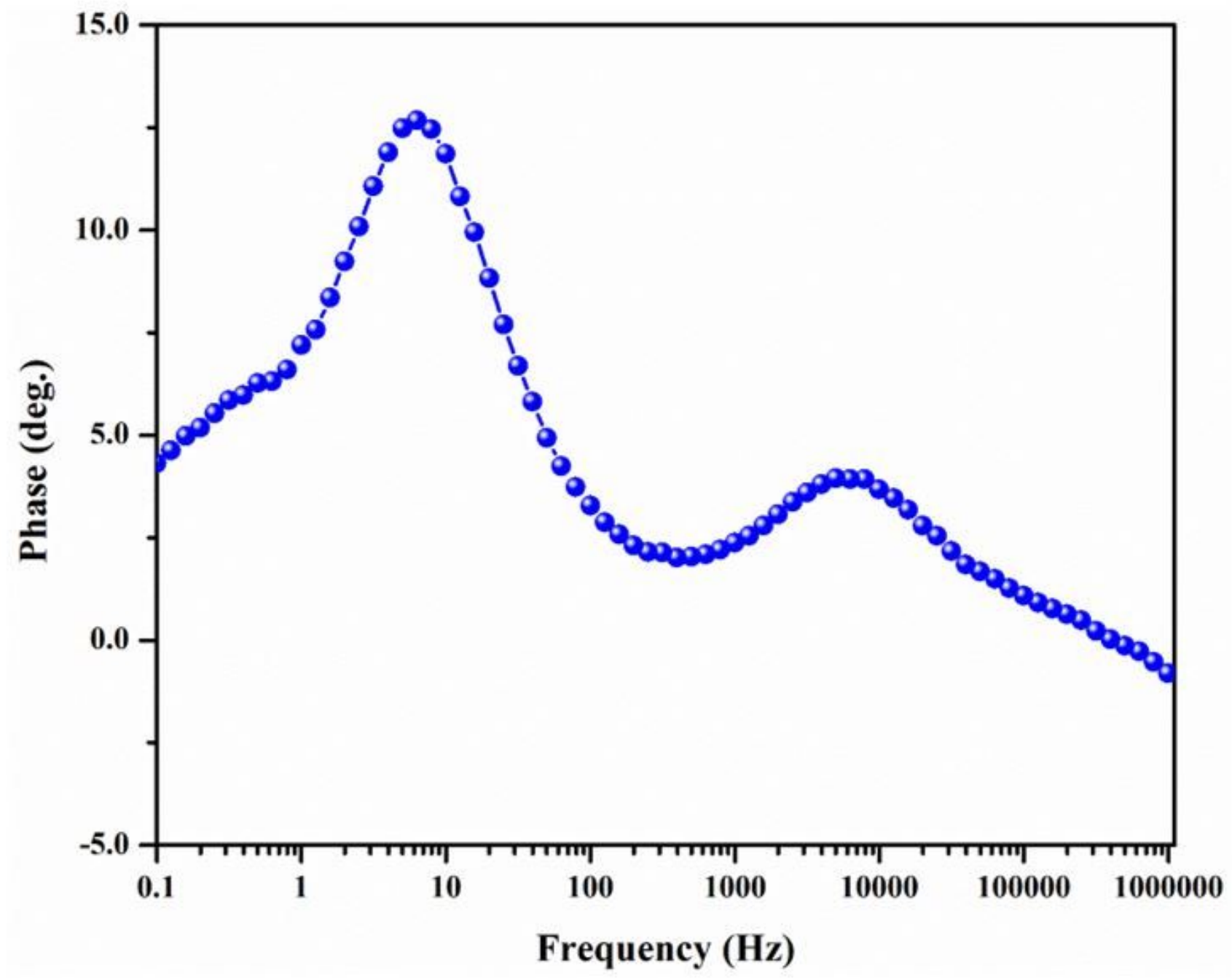

Figure 10

Bode plot for TiO2 MS-based DSSC 